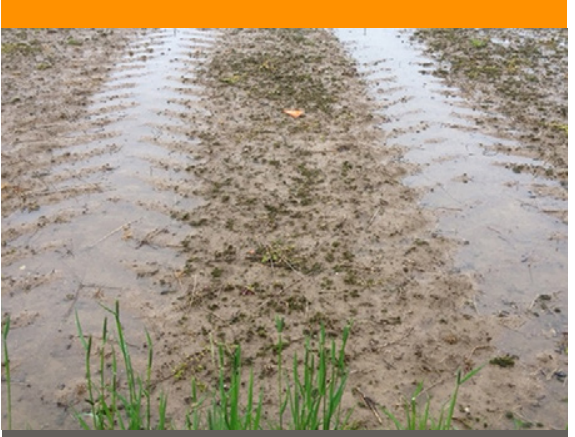

Core Ideas

- We provide long-term data on soil structure evolution following compaction.

- Treatments with and without plants and with and without tillage are included.

- Monitoring includes soil physical

and biological properties and crop measures.

- Compaction decreased fluid

transport capability and increased mechanical impedance.

T. Keller, M.P. Manalili J. Rek, V. Stadelmann, R. Reiser, H. Oberholzer, and P. Weisskopf, Agroscope, Dep. of Agroecology and Environment, Reckenholzstrasse 191, CH-8046 Zürich, Switzerland; T. Keller, Swedish Univ. of Agricultural Sciences, Dep. of Soil and Environment, Box 7014, SE-75007 Uppsala, Sweden; T. Colombi and A. Walter, Swiss Federal Institute of Technology ETH, Institute of Agricultural Sciences, Crop Science, Universitätstrasse 2, CH-8092 Zürich, Switzerland; S. Ruiz, H. Wunderli, D. Breitenstein, S. Schymanski, and D. Or, Swiss Federal Institute of Technology, Institute of Terrestrial Ecosystems (ITES), Soil and Terrestrial Environmental Physics (STEP), Universitätstrasse 16, CH-8092 Zürich, Switzerland; A. RomeroRuiz and N. Linde, Univ. of Lausanne, Institute of Earth Sciences, Applied and Environmental Geophysics Group, Bâtiment Géopolis, CH-1015 Lausanne, Switzerland. M.P. Manalili current address: Crop and Environmental Sciences Division, IRRI, Los Baños, Laguna, Philippines. $\quad{ }^{*}$ Corresponding author (thomas.keller@agroscope.admin.ch).

Vadose Zone J.

doi:10.2136/vzj2016.11.0118

Received 28 Nov. 2016.

Accepted 22 Feb. 2017.

Supplemental material online.

(c) Soil Science Society of America.

This is an open access article distributed

under the CC BY-NC-ND license

(http://creativecommons.org/licenses/

by-nc-nd/4.0/).

\section{Long-Term Soil Structure Observatory for Monitoring Post-Compaction Evolution of Soil Structure}

\author{
Thomas Keller, Tino Colombi, Siul Ruiz, Mervin Pogs \\ Manalili, Jan Rek, Viktor Stadelmann, Hans Wunderli, \\ Dani Breitenstein, René Reiser, Hansrudolf Oberholzer, \\ Stanislaus Schymanski, Alejandro Romero-Ruiz, Niklas \\ Linde, Peter Weisskopf, Achim Walter, and Dani Or
}

The projected intensification of agriculture to meet food targets of a rapidly growing world population are likely to accentuate already acute problems of soil compaction and deteriorating soil structure in many regions of the world. The key role of soil structure for soil functions, the sensitivity of soil structure to agronomic management practices, and the lack of reliable observations and metrics for soil structure recovery rates after compaction motivated the establishment of a long-term Soil Structure Observatory (SSO) at the Agroscope research institute in Zürich, Switzerland. The primary objective of the SSO is to provide long-term observation data on soil structure evolution after disturbance by compaction, enabling quantification of compaction recovery rates and times. The SSO was designed to provide information on recovery of compacted soil under different post-compaction soil management regimes, including natural recovery of bare and vegetated soil as well as recovery with and without soil tillage. This study focused on the design of the SSO and the characterization of the pre- and post-compaction state of the field. We deployed a monitoring network for continuous observation of soil state variables related to hydrologic and biophysical functions (soil water content, matric potential, temperature, soil air $\mathrm{O}_{2}$ and $\mathrm{CO}_{2}$ concentrations, $\mathrm{O}_{2}$ diffusion rates, and redox states) as well as periodic sampling and in situ measurements of infiltration, mechanical impedance, soil porosity, gas and water transport properties, crop yields, earthworm populations, and plot-scale geophysical measurements. Besides enabling quantification of recovery rates of compacted soil, we expect that data provided by the SSO will help improve our general understanding of soil structure dynamics.

Abbreviations: BS, bare soil; CEP, compaction of entire plot; CT, conventional tillage; CWT, compaction in wheel tracks; ERT, electrical resistivity tomography; FDR, frequency domain reflectometry; GPR, ground-penetrating radar; NOC, no compaction; NT, no-till; PG, permanent grass; SOC, soil organic carbon; SSO, Soil Structure Observatory.

Soil compaction due to agricultural operations is a serious threat to soil productivity and soil ecological functions in modern agriculture (Hamza and Anderson, 2005; Schjønning et al., 2015). The susceptibility of soil to compaction is a combination of inherent soil properties, soil moisture status at the time of field operations, soil and land management, and the machinery used. Soil compaction problems are therefore especially widespread in agriculture involving heavy machinery and/or moist soils; such is the case in large parts of Europe and North America or parts of South America and Australia. According to Jones et al. (2003), more than one third of European subsoils are highly susceptible to compaction, and Schjønning et al. (2015) suggested that a quarter of all European soils were compacted. Hamza and Anderson (2005) cited figures of compacted areas of $68 \mathrm{Mha}$ (worldwide), $33 \mathrm{Mha}$ (Europe), and $4 \mathrm{Mha}$ (Australian wheat belt). The aggravation of soil compaction is linked with modern trends of steadily 
increasing power and weight of agricultural vehicles and implements, which today may reach wheel loads in excess of $10 \mathrm{Mg}$ for self-propelled harvesters or slurry spreaders (Schjønning et al., 2015). Economical and efficiency considerations suggest no slowing of this trend unless a technological breakthrough or a paradigm shift (e.g., small autonomous vehicles, fixed tracks) would occur. Considering the increasing pressures on agriculture for production of food, fiber, and biofuels, the continual degradation of soil resources due to compaction is expected to escalate in the future. Many modern agricultural vehicles induce stresses in the soil that exceed the mechanical strength of soils under most conditions, resulting in soil deformation and modification of the spatial arrangement of soil constituents and voids (pores), altering a critical component of soil structure. The reduction in pore volume and the change in pore structure (size distribution, connectivity, tortuosity) decrease transport capability (fluid and gas transport by advection and diffusion) and water storage capacity, increase mechanical resistance for root growth, change prevailing chemical reactions and the availability of nutrients (anoxic conditions), and modify physical habitats of soil organisms. These changes consequently affect biodiversity and a range of ecosystem services including the production of food, fiber, and fuel, water provision and purification, and atmospheric regulation (e.g., Zhang et al., 2007).

The real costs of soil compaction are borne by the cumulative loss of soil functionality (e.g., yield loss in agricultural systems) following a significant compaction event, integrated over the time period until a soil has effectively recovered to its pre-compaction functionality. Hence, quantifying compaction costs (and therefore the severity of compaction) requires knowledge about soil structure recovery rates after compaction. We differentiate between instantaneous compaction impact and compaction damage (Fig. 1), and define instantaneous compaction impact as the immediate effect of a compaction event on soil functions, whereas compaction damage relates to the compaction effect integrated over the structure recovery time. Considering the conceptual sketch in Fig. 1, we may describe compaction damage $(\mathrm{CD})$ as

$$
\mathrm{CD}=\int\left(\mathrm{CI}\left\{1-\left[C_{\mathrm{r}}(t) \mathrm{d} t\right]\right\} \mathrm{d} t\right)
$$

where $\mathrm{CI}$ is the immediate compaction impact (immediate change in a soil metric), $C_{\mathrm{r}}$ is the soil structure recovery rate (a function of time), and $t$ is the elapsed time since compaction. The compaction damage can be expressed in terms of compaction costs, i.e., by valuation of ecosystem services, although this is not an easy exercise (e.g., Loomis et al., 2000; Farber et al., 2002). The costs of compaction relate to ecological costs but also to direct monetary value, e.g., for farmers in terms of reduced profit due to yield decline. A review of compaction costs was given by Chamen et al. (2015). We note that partial recovery times, e.g., 90\% recovery, are typically used in ecological studies (e.g., MacNeil et al., 2015). Partial recovery times provide more useful estimates because simplistic recovery functions (e.g., logarithmic functions) may display unrealistic asymptotic behavior at large recovery times (Webb and Wilshire, 1980; Webb, 2002). While recovery describes a process, resilience is defined as the ability to recover a property, capacity, or function to its initial value when the disturbance (i.e., stress) is removed (e.g., Lal, 1993; Gregory et al., 2007). Resilience is typically quantified in terms of a resilience index that relates the initial impact (i.e., impact at time 0 ) to the effect at time $x$ (e.g., Orwin and Wardle, 2004). Hence, resilience quantifies the amount of recovery at a certain time step after the disturbance.

Our knowledge regarding soil compaction recovery rates and recovery times is anecdotal and sketchy. Experimental evidence of compacted soil recovery periods from field studies suggests a wide range, from months (Drewry et al., 2004) and years (Culley et al., 1982; Blackwell et al., 1985; Langmaack et al., 1999; Radford et al., 2007; Besson et al., 2013) to decades (Håkansson and Reeder, 1994; Peng and Horn, 2008; Berisso et al., 2012) and centuries (Webb, 2002). In these studies, only a few properties and functions were addressed. Traditionally, crop yield has been the focus of such evaluations (e.g., Culley et al., 1982; Håkansson and Reeder, 1994), while more recent work has addressed soil structure and transport functions (e.g., Peng and Horn, 2008; Berisso et al., 2012; Besson et al., 2013) or earthworm abundance (Langmaack et al., 1999). Estimates of recovery rates based on laboratory studies (e.g., Arthur et al., 2013) are typically higher than those observed in field studies, thus potentially underestimating recovery times and compaction costs. The conflicting evidence of compaction recovery times, and the discrepancy in recovery rate estimates between

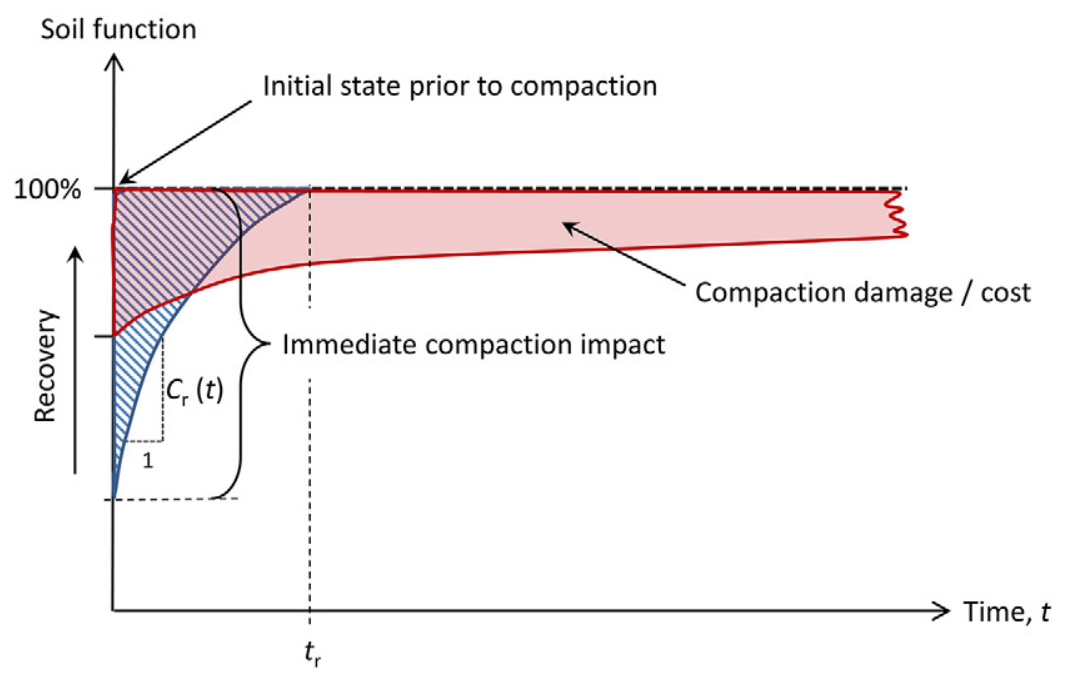

Fig. 1. Schematic figure showing immediate compaction impact, compaction recovery rate $C_{\mathrm{r}}(t)$, compaction recovery time $t_{\mathrm{r}}$, and compaction damage. Case 1 in blue indicates a large immediate impact but a fast recovery, thus moderate damage (e.g., topsoil compaction), while Case 2 (red) shows a moderate immediate impact but slow recovery, thus large damage (e.g., subsoil compaction). 
field and laboratory studies, is a manifestation of the partial and incomplete knowledge of the key processes involved in soil structure recovery and, more generally, soil structure dynamics. Although the relevant mechanisms are generally well established, their quantitative and predictive representation remain limited. The key natural mechanisms involved in soil structure recovery following compaction are grouped according to climatic and abiotic processes induced by wetting-drying and freezing-thawing phenomena, and biotic processes (root growth and root water uptake, burrowing of earthworms and other soil fauna, microbiological activity). Additionally, anthropogenic effects such as mechanical loosening and fragmentation by soil tillage play an important role in enhancing soil structure recovery. It is clear, however, that one-time tillage cannot simply reverse compaction effects, and it has been shown that compaction effects persist in the tilled layer for several years despite regular tillage (Arvidsson and Håkansson, 1996; Weisskopf et al., 2010).

A more definitive understanding of compacted soil recovery rates and times is not only needed for estimation of the real costs of compaction (see above and Fig. 1), but a more quantitative description of natural compaction recovery mechanisms and recovery pathways could also be used to develop site-specific soil management methods (or strategies) that accelerate compaction recovery (Dexter, 1991). More generally, improved understanding of soil structure dynamics due to biophysical processes could offer a path for harnessing biological processes to improve the physical and ecological conditions of soil for agricultural production (Dexter, 1991; Hallett et al., 2013). Protocols for enhancing soil structure recovery (and more generally, soil structure formation) are urgently needed, with the growing threat of soil compaction as a result of the intensification of agriculture to enhance food production.

A framework for combining in situ monitoring, modeling, and small-scale mechanistic experiments targeting the different compaction recovery processes is necessary to better understand the complex biophysical interactions and feedback mechanisms involved in soil structure dynamics. A major gap in our knowledge of soil structure dynamics as identified above is the discrepancy in temporal and spatial scales between laboratory investigations and field studies under natural climatic conditions and the lack of systematic field observations at the proper (i.e., years to decades) time scale. Consequently, research on soil structure evolution requires, among others, long-term field studies including adequate research infrastructure for monitoring.

To address these challenges, we designed a long-term field experiment for monitoring post-compaction evolution of soil structure, referred to as a soil structure observatory. Here we describe the objectives, the design, the implementation, and monitoring concept of our soil structure observatory and present the initial compaction effects.

\section{The Soil Structure Observatory}

\section{Conceptual Approach, Rationale, and Motivation}

An appropriate time (several years to decades) and spatial scale (plot scale or larger) is crucial for an adequate monitoring of soil structure recovery after compaction. Further key design factors include monitoring of climatic variables (precipitation, temperature, etc.), monitoring of soil state variables, and observations of soil and crop properties at regular intervals.

The general aim of the Soil Structure Observatory (SSO) is to provide long-term observation data on soil structure evolution after disturbance in the form of compaction. This will allow quantification of compaction recovery rates and times and therefore quantification of compaction costs (cf. Fig. 1). We aim at combining the data obtained from the SSO with modeling and small-scale mechanistic experiments to increase our understanding of soil structure dynamics and particularly soil structure recovery after compaction. The SSO may hereby serve as a platform for integrating the contemporary knowledge that is currently fragmented across temporal and spatial scales.

The SSO was designed to provide information on both the natural recovery of compacted soil structure and evaluation of soil management options (e.g., soil tillage) for accelerating soil structure (and function) recovery. Consequently, the SSO includes treatments with and without interference by farming operations. Moreover, we intended to isolate, as much as possible, predominantly physical natural recovery (i.e., without plants and limited soil fauna) from combined biological and physical natural recovery. Hence, treatments with and without plants and without any mechanical post-compaction disturbance were included in the SSO. In these treatments, it is important to prohibit any field traffic after the initial experimental compaction to study the natural recovery of soil structure after compaction. This substantially increases operational demands on the infrastructure (e.g., fencing) as well as workload in the field because all field operations have to be performed by hand. The SSO has been designed to test the following main hypotheses:

- Soil structure recovery is accompanied by measureable changes in soil biophysical properties and crop performance

- Biological activity increases the rate of soil structure recovery

- Tillage facilitates soil structure recovery

- Roots and soil mesofauna (e.g., earthworms) avoid compacted zones when possible (such as wheel tracks).

\section{Study Site and Pre-compaction Field Management}

The SSO was established on a deep gleyic Cambisol (IUSS Working Group WRB, 2006) with loamy soil texture (see Table 1) at the 
Agroscope research institute in Zürich, Switzerland $\left(47.4^{\circ} \mathrm{N}, 8.5^{\circ}\right.$ $\mathrm{E} ; 444 \mathrm{~m}$ asl). The mean annual temperature is $9.4^{\circ} \mathrm{C}$, and the mean annual precipitation is $1054 \mathrm{~mm}$ (data obtained from the Swiss Federal Office of Meteorology and Climatology, MeteoSwiss). The SSO is designed as a decade-long (or longer) observatory. Selected soil properties are presented in Tables 1 and 2 .

The site $(\sim 1.5 \mathrm{ha})$ was sown with a grass mixture in April 2013, roughly 1 yr before initiating soil compaction in March 2014. We used the grass-white clover (Trifolium repens L.) mixture SM 442 (Suter et al., 2008) reinforced with an additional $4 \mathrm{~kg} \mathrm{ha}^{-1}$ of lucerne (Medicago sativa L.). This grass mixture was chosen because it contains species with different root systems and depthdistributions of roots, and because it is known to be robust under a wide range of unfavorable soil physical conditions (e.g., water logging and $\mathrm{O}_{2}$ stress). After sowing the mixture, no more traffic with agricultural machinery was allowed over the experimental area, except for a small self-propelled mower used for periodic cutting of the grass. The initiation of the ley $1 \mathrm{yr}$ prior to initial compaction and the prohibition of any farm machinery traffic aimed at allowing the soil to "rest" before establishing the SSO.

A permanent meteorological station run by MeteoSwiss is located within $300 \mathrm{~m}$ from the experimental field, delivering hourly data on, among others, air temperature, precipitation, relative humidity, and global radiation.

\section{Experimental Design}

The SSO includes two experimental factors - compaction level and post-compaction soil management (see below) — and is based on a strip-plot design (Fig. 2) with three blocks (replicates). There are three compaction levels and four management treatments, as detailed below, amounting to a total of 36 plots. Each plot is $17 \mathrm{~m}$ long and 10 to $12 \mathrm{~m}$ wide. A one-time compaction was performed in the in-sown ley (see above) in March 2014, and the four postcompaction soil management treatments were immediately started thereafter. Thus, the (soil) conditions during compaction were the same (ley) in all treatments. No further experimental compaction is foreseen in the SSO.

\section{Compaction Treatments}

The SSO includes three compaction levels (Fig. 2): compaction of the entire plot area, i.e., track-by-track (CEP), compaction in wheel tracks (CWT), and control, i.e., no experimental compaction (NOC). The same compaction intensity (i.e., the same machinery and the same number of machinery passes) was applied in CEP and CWT.

Treatment CWT allows studying soil structure evolution under conditions where roots and soil organisms can avoid compacted zones (wheel tracks) (Capowiez et al., 2009), in comparison with processes under CEP, where the entire near-surface volume is compacted. Soil compaction recovery might be slower in the compacted zones under the wheel tracks if roots and soil organisms

Table 1. Basic soil properties at the Soil Structure Observatory, Zürich, Switzerland.

\begin{tabular}{|c|c|c|c|c|c|c|c|}
\hline Block & $\begin{array}{l}\text { Clay } \\
(<2 \mu \mathrm{m})\end{array}$ & $\begin{array}{l}\text { Silt } \\
(2-50 \mu \mathrm{m})\end{array}$ & $\begin{array}{l}\text { Sand } \\
(50-2000 \mu \mathrm{m})\end{array}$ & Organic C & Particle density & $\mathrm{pH}\left(\mathrm{CaCl}_{2}\right)$ & $\begin{array}{l}\text { Cation exchange } \\
\text { capacity }\end{array}$ \\
\hline \multicolumn{5}{|c|}{$0-0.2$-m depth } & \multicolumn{2}{|l|}{$\mathrm{Mg} \mathrm{m}^{-3}$} & $\mathrm{cmol}_{\mathrm{c}} \mathrm{kg}^{-1}$ \\
\hline A & $0.254(0.014) \dagger$ & $0.518(0.015)$ & $0.228(0.018)$ & $0.018(0.001)$ & 2.56 & $6.3(0.3)$ & $17.4(0.6)$ \\
\hline B & $0.273(0.014)$ & $0.486(0.040)$ & $0.241(0.040)$ & $0.017(0.001)$ & 2.62 & $7.1(0.2)$ & $17.8(0.7)$ \\
\hline A & $0.307(0.018)$ & $0.487(0.017)$ & $0.206(0.030)$ & $0.008(0.000)$ & 2.60 & $6.6(0.3)$ & $18.0(0.6)$ \\
\hline $\mathrm{C}$ & $0.269(0.038)$ & $0.450(0.026)$ & $0.281(0.054)$ & $0.007(0.004)$ & 2.65 & $7.4(0.2)$ & $15.3(2.6)$ \\
\hline
\end{tabular}

† Means and standard deviations (in parentheses) of 12 (topsoil) and eight (subsoil) sampling locations.

Table 2. Soil physical and biological properties prior to compaction, from samples taken during October 2013, i.e., 5 mo before the compaction event, including bulk density (BD), total porosity (TP), air-filled porosity at $100 \mathrm{hPa}$ water suction $\left(\varepsilon_{\mathrm{a}, 100 \mathrm{hPa}}\right)$, relative gas diffusion coefficient at $100 \mathrm{hPa}$ water suction $\left(D_{\mathrm{p}, 100 \mathrm{hPa}} / D_{0}\right)$, air permeability at $100 \mathrm{hPa}$ water suction $\left(k_{\mathrm{a}, 100 \mathrm{hPa}}\right)$, saturated hydraulic conductivity $\left(K_{\text {sat }}\right)$, microbial biomass $(\mathrm{MB}$, as microbial $\left.\mathrm{C}\left[\mathrm{C}_{\mathrm{mic}}\right]\right)$, and basal respiration $(\mathrm{BR})$.

\begin{tabular}{|c|c|c|c|c|c|c|c|c|}
\hline Depth & $\mathrm{BD}$ & $\mathrm{TP}$ & $\varepsilon_{\mathrm{a}, 100 \mathrm{hPa}}$ & $D_{\mathrm{p}, 100 \mathrm{hPa}} / D_{0}$ & $\log k_{\mathrm{a}, 100 \mathrm{hPa}}$ & $\log K_{\text {sat }}$ & MB & $\mathrm{BR}$ \\
\hline $\mathrm{m}$ & $\mathrm{Mg} \mathrm{m}^{-3}$ & 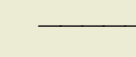 & $m^{-3}$ & & $\log \mu \mathrm{m}^{2}$ & $\log m m h^{-1}$ & $\mathrm{mg} \mathrm{C}_{\mathrm{mic}} \mathrm{kg}^{-1}$ & $\mu \mathrm{gCO}_{2}-\mathrm{Cg}^{-1} \mathrm{~h}^{-1}$ \\
\hline 0.1 & $1.38(0.01) \dagger$ & $0.47(0.01)$ & $0.09(0.01)$ & $0.019(0.002)$ & $1.29(0.15)$ & $2.08(0.07)$ & $482.5 \neq(15.4)$ & $0.55 \neq(0.05)$ \\
\hline 0.3 & $1.52(0.01)$ & $0.42(0.01)$ & $0.06(0.01)$ & $0.010(0.001)$ & $0.93(0.02)$ & $2.18(0.20)$ & $161.8 \$(0.81)$ & $0.33 \S(0.10)$ \\
\hline 0.6 & $1.53(0.03)$ & $0.42(0.01)$ & $0.04(0.01)$ & $0.005(0.001)$ & $0.43(0.07)$ & $1.63(0.10)$ & & \\
\hline
\end{tabular}

$\dagger$ Means and standard errors (in parentheses; $n=3$ experimental blocks).

$\neq 0-0.2$ - $\mathrm{m}$ depth.

$\S 0.3-0.5$-m depth. 
Block A

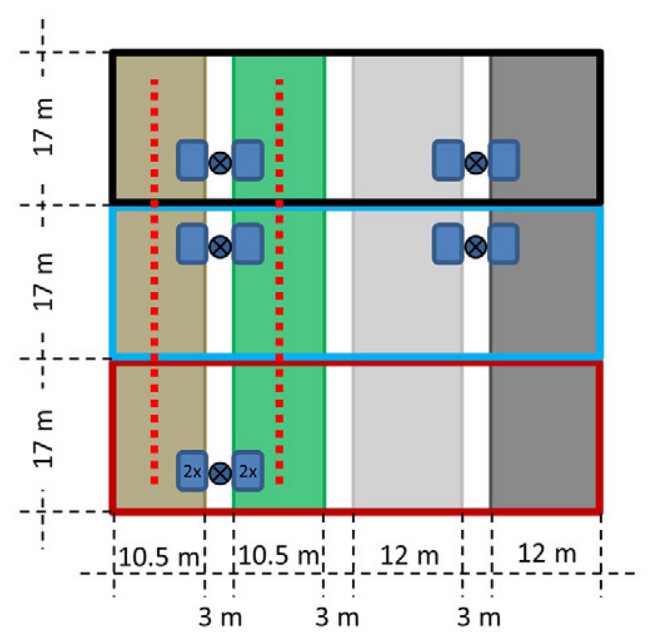

Block B

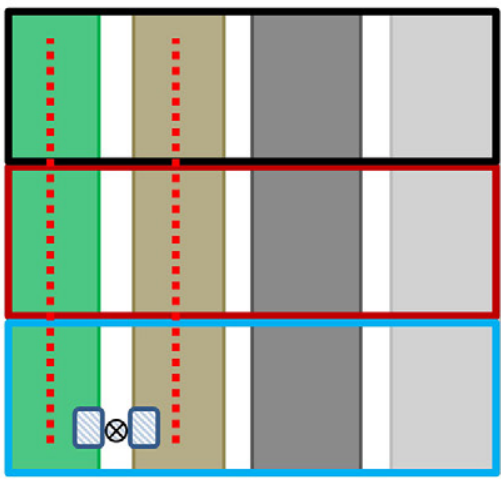

Block C

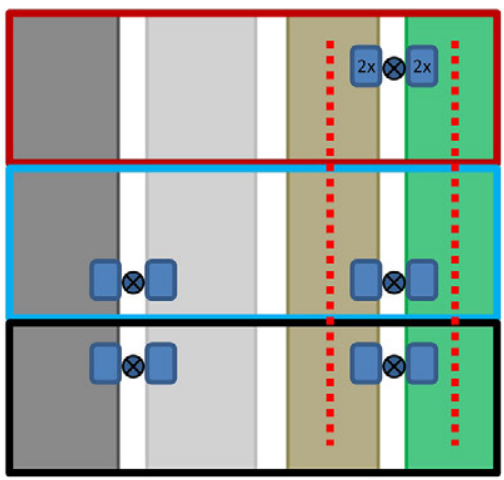

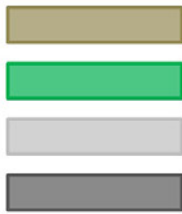

Bare soil

Permanent grass

No tillage

Conventional tillage

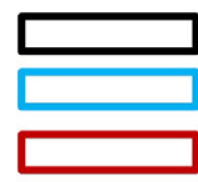

Compaction whole surface

Control

Compaction tracks

$1 \mathbb{Q}$ Sensor bank: full / reduced installation

$\otimes / \otimes$ Logger station

2x Two sensor banks (center and edge of track)

.... ERT transects

Fig. 2. Experimental design of the Soil Structure Observatory (SSO) in Zürich, Switzerland.

avoid these zones. On the other hand, it could be argued that recovery in CWT would be faster than in CEP because the compacted zone has a larger interface with uncompacted soil, from which recovery could be initiated. Treatment CWT would more often occur in practice; however, modern agricultural machinery (e.g., self-propelled sugarbeet harvesters, self-propelled forage harvesters, self-propelled slurry tankers) are equipped with offset steering and therefore track the entire surface area as in treatment CEP.

\section{Post-compaction Soil Management and Cropping Systems}

The SSO includes four post-compaction soil management-cropping systems: bare soil (BS), permanent grass (PG), crop rotation under no-till (NT), and crop rotation under conventional tillage (CT). No farming traffic and no mechanical disturbance are allowed in systems BS and PG; these systems therefore provide insights into uninterrupted natural processes of soil structure regeneration, with plants signifying normal biological activity (PG) and without plants suggesting reduced biological activity (BS). The two cropping systems (NT and CT) enable insights into soil structure recovery under common agricultural practices with minimal (NT) and conventional mechanical soil disturbance (CT).

Plants on the bare soil treatments (BS) are suppressed by periodic application of nonselective herbicides (glyphosate [ $N$-(phosphonomethyl)glycine], glufosinate-ammonium [2-amino4-(hydroxymethylphosphinyl)butanoic acid monoammonium salt]). The herbicide is applied manually using a knapsack sprayer with a $2.5-\mathrm{m}$ swath width. The treatment PG represents a grass mixture that was established in spring 2013 (see above), i.e., the grass survived the compaction without any resowing. The grass is cut four to five times per year using a small self-propelled motor mower (total mass $\sim 200 \mathrm{~kg}$ ). The cut grass is then manually removed from the experimental area.

Triticale ( $\times$ Triticosecale, cultivar Trado) was sown in the NT and CT plots on 3 Apr. 2014, i.e., 8 d after compaction. Glyphosate was applied to the BS and NT plots on 29 Mar. 2014 to control the ley that was established in 2013 (see above). The crop was sown without any prior tillage with a no-till drill in the NT plots, while the soil was moldboard plowed to about $0.25 \mathrm{~m}$ and harrowed to about the 0.06-m depth using a rotavator on $2 \mathrm{Apr}$. 2014 in the CT plots. Fertilization of the NT and CT plots is performed according to the Swiss fertilization recommendation (GRUDAF) (Flisch et al., 2009), and crop protection (weed and disease control) in NT and CT is done according to the principles of "integrated pest management" aiming to suppress pest populations below the economic injury level, largely relying on pesticides. The crop rotation for NT and CT, to date, is: triticale ( $\times$ Triticosecale, 2014)-silage maize (Zea mays L., 2015)-winter wheat (Triticum aestivum L., 2016)-winter rapeseed (Brassica napus L., 2017).

\section{Monitoring and Sampling Concept}

Observations at the SSO include continuous monitoring of soil state variables (soil moisture, temperature, soil air $\mathrm{CO}_{2}$ and $\mathrm{O}_{2}$ 
concentrations, redox potential, and $\mathrm{O}_{2}$ diffusion rates), for which a network of sensors was installed at various depths $(0-1 \mathrm{~m})$, and periodic sampling and measurements of soil physical, chemical, and biological properties, earthworm abundance, and crop measures. The monitoring and measurements cover different spatial scales: soil core, soil profile (e.g., root characteristics), and the plot scale (e.g., geophysical measurements, crop biomass). The observation scheme includes pre-compaction soil characterization (October 2013), measurements during the compaction event (March 2014), post-compaction soil characterization (March-May 2014), and post-compaction monitoring (April 2014 to date). An overview of all the measurements is provided in Supplemental Table S1.

Soil sampling and in situ measurements during pre-compaction soil characterization were performed at 12 randomly selected sampling or measuring locations per experimental block. Earthworm sampling was done at five randomly selected locations within each block. Geophysical measurements were performed in transects, with one electrical resistivity tomography (ERT) transect (48 electrodes, 1-m spacing) per block and three ground-penetrating radar (GPR) transects per block (one transect in the north-south direction and two in the east-west direction). Selected soil properties measured during the pre-compaction soil characterization are given in Table 2. The ERT and GPR results revealed only subtle lateral heterogeneities within and between transects, thereby indicating similar soil profiles across the SSO.

Post-compaction soil characterization was done 2 wk after compaction except for earthworm sampling, which was performed 2 mo after compaction. Three sampling or measuring locations were randomly selected in each NOC and CEP plot. For CWT, sampling or measuring was done at three positions, namely the track center, track edge, and between tracks, with three randomly selected sampling or measuring locations per plot for each position, amounting to a total of nine sampling or measuring locations in each CWT plot. Earthworms were sampled at two randomly selected locations per experimental block in the CEP and NOC plots.

Sampling and measurements during post-compaction monitoring will be performed at intervals of half a year (within the first 1-2 yr after compaction) to $1 \mathrm{yr}$ (from the third year after compaction; and possibly larger time intervals at later stages). The sampling and measuring locations will be randomly selected within each plot. A minimum distance between plot edge and sampling and measuring locations of $1 \mathrm{~m}$, as well as a minimum distance between previous and subsequent sampling and measuring locations of $1 \mathrm{~m}$ will be considered. The post-compaction monitoring includes fewer sampling or measuring locations than the post-compaction characterization and may not always include all sampling depths because recovery is expected to be slower at greater depths. Additional measurements such as greenhouse gas emissions could potentially be added later or for some periods of time.

\section{Compaction Stresses in the Soil}

During the compaction event, we measured soil mechanical stresses at the 0.2-, 0.4-, and 0.6-m depth using custom-made Bolling probes (Bolling, 1987), which are fluid-inclusion-type probes used to determine mean normal stress (Berli et al., 2006). These measurements were performed between the three experimental blocks (Fig. 2) to avoid damaging the experimental plots. The Bolling probes were installed as described by Keller et al. (2016). We acquired information from four field replicates, i.e., we installed the probes at four different locations within the field. We collected undisturbed soil samples (0.1-m diameter, 0.06-m height) at depths of $0.2,0.4$, and $0.6 \mathrm{~m}$. Sampling locations were adjacent to the locations of soil stress measurements for determination of Poisson's ratio, $v$, in the laboratory according to the method of Eggers et al. (2006) based on uniaxial confined and unconfined compression tests. The mean normal stress, $\sigma_{\mathrm{m}}$, was then calculated from the Bolling probe pressure, $p_{\mathrm{i}}$, and $v$ using Eq. [20] and [23] of Berli et al. (2006).

\section{Monitoring Changes in Soil Surface Elevation Using Lidar}

As part of the monitoring, we examined the potential of a modern lidar system for capturing soil surface elevation changes due to the prescribed compaction treatment and subsequent rebound. Such a system requires reference points of known position and elevation, so that measurements can be translated to surface elevation changes. Six ground screws (0.8 m in length; Krinner $\mathrm{GmbH}$ ), serving as fixed points, were drilled into the soil at positions between the experimental plots. During measurements (scanning), spherical targets mounted on $\sim 1.5$-m-long aluminum rods are fixed to the ground screws, defining a fixed coordinate system (see also Friedli et al., 2016). Measurements were performed using a Faro Focus 3D S 120 laser scanner (Faro Technologies Inc.) that was mounted on a tripod at a height of about $3.5 \mathrm{~m}$ (Friedli et al., 2016). See Friedli et al. (2016) for more details on the scanner and the field setup.

An additional setup was used to perform scans immediately before compaction, immediately after trafficking, and $0.5,1$, and $2 \mathrm{~h}$ after trafficking, to quantify vertical surface displacements and potential rebound effects. Wooden square reference plates of $0.25 \mathrm{~m}^{2}$ were placed into the center of two experimental plots (one plate per plot) after the vegetation was cut. Three spheres of 0.1-m diameter mounted on poles at a height of $0.75 \mathrm{~m}$ were arranged in a triangle and served as reference points to determine the displacement of the plates. The scanner was mounted on a tripod at a height of $3.5 \mathrm{~m}$ above the land surface. The horizontal distance from the scanner to the plates was $12.5 \mathrm{~m}$, and the distance to the spheres was $1 \mathrm{~m}$ (one sphere) and $25 \mathrm{~m}$ (two far-off spheres). Scans were performed with a measuring rate of 244,000 scan points per second at half of the maximum resolution provided by the system. The distances between single scan points on the plates and the far-off spheres were 3.9 and $7.7 \mathrm{~mm}$, respectively. 


\section{In Situ Sensors for Monitoring Physicochemical Soil State Variables}

Sensor probe banks (Fig. 2) consisting of probes at various depths (Fig. 3) were installed post-compaction for continuous monitoring of the evolution of soil moisture states, soil temperature, soil air composition $\left(\mathrm{O}_{2}\right.$ and $\mathrm{CO}_{2}$ concentrations), $\mathrm{O}_{2}$ diffusion rates, and redox states. Installation started $5 \mathrm{~d}$ after the compaction event and was completed $10 \mathrm{~d}$ after the compaction event. Two banks were established in the CWT plots (Fig. 2): one in the center and one at the edge of a wheel track. The depths considered were 0.1, 0.2 , and $0.4 \mathrm{~m}$ (all probes), and additionally 0.7 and $1 \mathrm{~m}$ (soil moisture probes). The probes were installed either horizontally from a pit or from above ground (Fig. 3). The distance between plot edge and sensing head was at least $0.6 \mathrm{~m}$. In each bank, two to four replicate probes were installed per depth. Probes at the 0.1 - and $0.2-\mathrm{m}$ depths in the CT plots are removed and reinstalled at each tillage occasion. The sensor system was automated using CR800 and CR1000 dataloggers and AM16/32B multiplexers (all from Campbell Scientific Ltd.). Wired connection of the sensors to the dataloggers and multiplexers started as soon as the sensor probes were in the ground, but completion of the datalogging system took several weeks. Data are recorded every $30 \mathrm{~min}$ (for technical reasons, readings of redox potentials and $\mathrm{O}_{2}$ diffusion rates are taken only every $8 \mathrm{~h}$; see below) and automatically transferred via General Packet Radio Service (GPRS) communication to a database on a web server (WebDAVIS 3.0, Solexperts AG).

The soil moisture conditions are monitored by measuring soil water suction and soil water content. Soil water suction is measured with a combination of tensiometers (in-house production; Klute, 1986) and calibrated heat dissipation sensors (pF-Meter, ecoTech). The latter sensors yield indirect matric potential measurements and were installed due to the limited range of tensiometers in dry soil (tensiometers fail at water suctions $>800$ $\mathrm{hPa}$ ). Soil water content is measured using in-house-produced three-prong time-domain reflectometry (TDR) probes (Jones et al., 2002) and frequency-domain reflectometry (FDR) profilers (EnviroScan, Sentek). The FDR profilers are easily removed from the soil, an operation that needs to be done in the two crop rotation treatments (CT and NT) during field operations (soil tillage, seeding). Some plots are equipped with both TDR and FDR sensors to allow cross comparisons. Two FDR profilers and two tensiometers per depth were installed in Block B at the end of summer 2013 (i.e., more than half a year before the compaction event). Apart from getting a "general feeling" for the soil water dynamics of the site, measurements from these probes were used to define an appropriate time for the compaction event (e.g., soil water content similar to the soil water content at the maximum Proctor density; ASTM, 1992; Aragón et al., 2000; Botta et al., 2008). Soil temperature is measured using standard copperconstantan thermocouples. Soil temperature dynamics affect biological activity and may also carry a structural signature (e.g., higher thermal conductivity for compacted layers).
Redox potentials $\left(\mathrm{E}_{\mathrm{H}}\right)$ and $\mathrm{O}_{2}$ diffusion rates (ODR) are monitored with a system consisting of Pt glass electrodes, calomel reference electrodes, and a brass anode, as detailed by Reiser et al. (2012). An 8-h logging interval, from one $\mathrm{E}_{\mathrm{H}}-\mathrm{ODR}$ data pair to the next, allows relaxation of the electrode polarization and regeneration of the depleted $\mathrm{O}_{2}$ concentration near the Pt electrode.

Soil $\mathrm{O}_{2}$ and $\mathrm{CO}_{2}$ concentrations were initially measured manually at biweekly intervals according to a method described by Weisskopf et al. (2010). Porous polypropylene tubes of 0.5 -m length were horizontally installed at the 0.1-, 0.2-, and 0.4-m depths for measurements of $\mathrm{O}_{2}$ and $\mathrm{CO}_{2}$ concentrations in the soil air using a CheckMate 9900 head space gas analyzer (PBI Dan-sensor A/S). Probes for continuous measurements were developed later.

\section{Electrical Resistivity Tomography Monitoring and Ground Penetrating Radar}

Repeated (two to three times per year) ERT measurements are performed in the SSO in an attempt to observe geophysical signatures of structural changes with time at the plot scale. Stainless steel electrodes were installed along transects (48 electrodes per transect; electrode spacing: $1 \mathrm{~m}$ ) in the BS and PG plots, as indicated in Fig. 2. The electrodes were left in the ground to ensure that subsequent data acquisitions were acquired with exactly the same electrode geometry. This enables more consistent interpretations and makes it possible to use advanced time-lapse inversion strategies. The ERT data are acquired using a Syscal Switch Pro system (http://www.iris-instruments.com) in a Wenner-Schlumberger electrode configuration. The ERT data are inverted using the algorithm described by Günther et al. (2006) and implemented in the BERT software. Ground-penetrating radar measurements are performed using dual-frequency antennas operating at 300 and $800 \mathrm{MHz}$ (UtilityScan DF by GSSI). The GPR data are analyzed using Reflexw (Sandmeier geophysical research) and in-house MATLAB scripts.

\section{Soil Geochemical Properties}

Soil samples are taken from the 0.0 - to 0.2 - and 0.3 - to 0.5 -m depth intervals. Soil texture is measured using the pipette method. Soil organic C (SOC) is determined by the wet combustion technique following ISO 10694. Soil $\mathrm{pH}$ was measured in $\mathrm{CaCl}_{2}$. Total $\mathrm{N}$ is measured using the Dumas combustion method with an element analyzer (varioMAX CNAnalyser, Elementar Analysensysteme $\mathrm{GmbH}$ ) (ISO 13878). The concentrations of exchangeable bases, i.e., $\mathrm{Ca}, \mathrm{K}, \mathrm{Mg}, \mathrm{Na}$, and $\mathrm{P}$, are measured by the $\mathrm{NH}_{4} \mathrm{OAc}$ method at $\mathrm{pH}$ 4.65. All analyses are performed according to Swiss standard protocols (Swiss Federal Research Stations, 1996).

\section{Microbial Biomass}

Soil samples are collected at two different depths, 0.0 to 0.2 and 0.3 to $0.5 \mathrm{~m}$. Soil microbial biomass is obtained by two methods: as $\mathrm{C}_{\text {mic }}$ estimated according to Anderson and Domsch (1978) and as $\mathrm{C}_{\text {mic }}$-SIR calculated from soil initial respiration (SIR) rates 


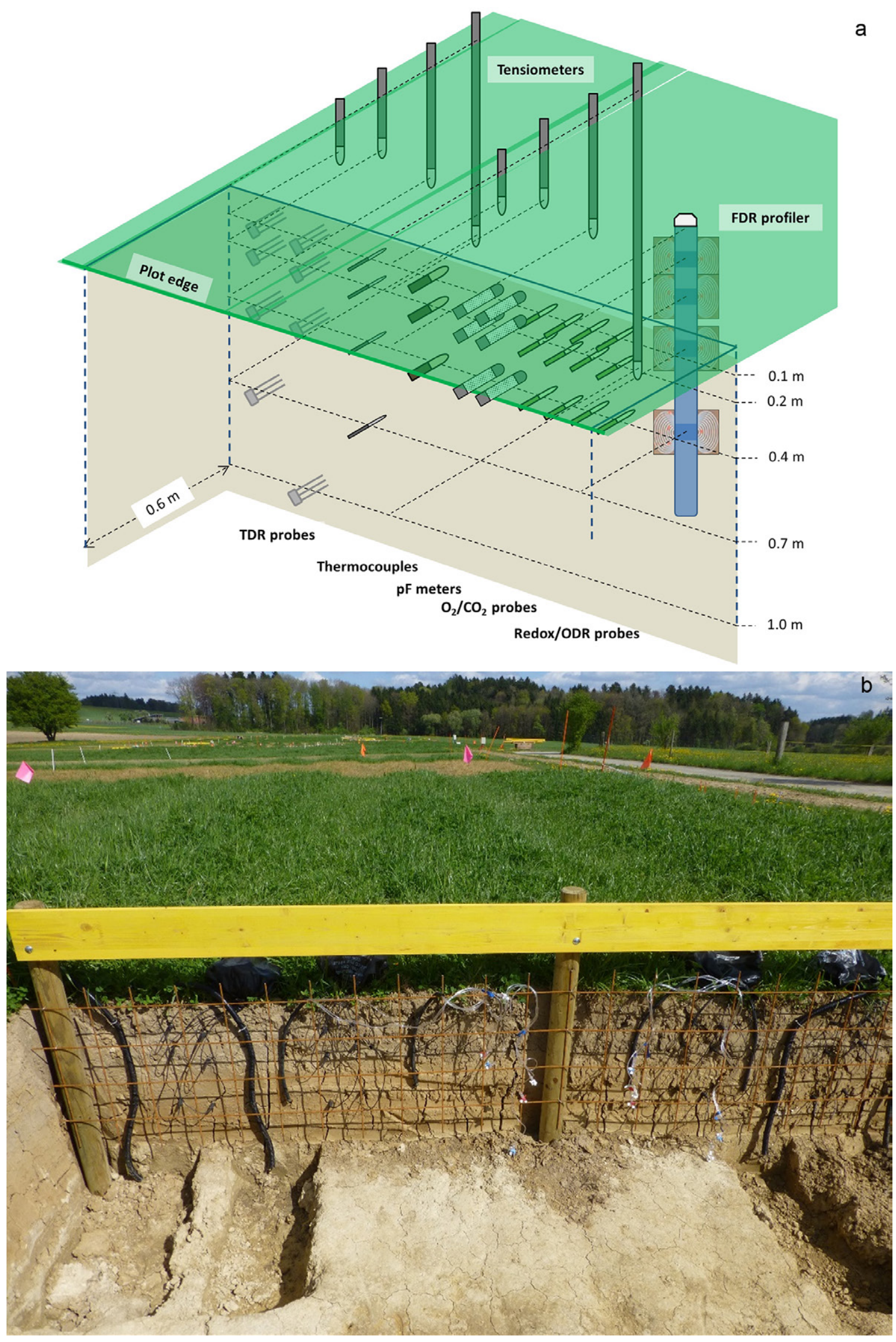

Fig. 3. (a) Schematic overview of a sensor bank, showing number and depths $(0.1,0.2,0.4,0.7$, and $1.0 \mathrm{~m})$ of the various sensor probes (but not necessarily the exact locations) installed from a profile wall at the plot edge through drilled holes of 0.6-m length; and (b) photo of a sensor bank where soil probes have been installed into the profile wall at various depths. The profile wall is at the plot edge. 
according to Kaiser et al. (1992). Soil basal respiration is measured in preincubated samples $\left(20 \mathrm{~g}\right.$ soil dry matter for $7 \mathrm{~d}$ at $22^{\circ} \mathrm{C}$ ) as $\mathrm{CO}_{2}$ evolved during a period of $48 \mathrm{~h}$ (from the 24 th to the $72 \mathrm{nd} \mathrm{h}$ of incubation). All measurements are done according to the reference methods of the Swiss Agricultural Research Stations (Swiss Federal Research Stations, 1996).

\section{Undisturbed Cylindrical Soil Cores for Characterization of Soil Structure}

Undisturbed cylindrical soil cores $\left(100 \mathrm{~cm}^{3}\right.$; diameter: $0.05 \mathrm{~m}$; height: $0.05 \mathrm{~m}$ ) are sampled at the 0.1-, 0.3-, and 0.6-m depth. The samples are stored at $2^{\circ} \mathrm{C}$ until measurements are done. On each sample, saturated hydraulic conductivity and air permeability and gas diffusivity at three levels of water suction $(30,100$, and $300 \mathrm{hPa})$ are measured in the laboratory. Saturated hydraulic conductivity is measured using the constant-head method (Klute and Dirksen, 1986). Air permeability is obtained by measuring the air flow through the sample at an overpressure of $2 \mathrm{hPa}$, and gas diffusivity is measured in a one-chamber apparatus that uses $\mathrm{O}_{2}$ as the diffusing gas assuming steady-state diffusion (Martínez et al., 2016). A subset of the soil core samples is scanned at $100 \mathrm{hPa}$ water suction with X-ray micro-computed tomography (Phoenix Votmex x s 240, GE Sensing and Inspection Technologies $\mathrm{GmbH}$ ) for visualization and characterization of soil pore architecture. The soil cores are dried in an oven at $105^{\circ} \mathrm{C}$ for at least $48 \mathrm{~h}$ after the various measurements, and the water content and bulk density are calculated.

\section{Penetration Resistance and Water Infiltration}

Penetrometer resistance is measured by means of a hand-pushed Eijkelkamp cone penetrometer (cone base area $1 \mathrm{~cm}^{2}$, cone apex angle $60^{\circ}$ ) to a depth of $0.8 \mathrm{~m}$. Two insertions are made at each sampling location.

Steady-state infiltration is measured at the soil surface using a disk permeameter (diameter: $0.2 \mathrm{~m}$ ) (Perroux and White, 1988). Two infiltration measurements per sampling location are made. The infiltration rates are derived from the cumulative infiltration vs. time relationship.

\section{Earthworm Abundance and Biomass}

Earthworms are sampled in an area of 0.5 by $0.5 \mathrm{~m}$ using the following procedure. The top $\sim 0.3 \mathrm{~m}$ of soil is excavated, and earthworms are collected by hand sorting. Then a $0.5 \%$ formaldehyde solution is applied to repel and thus extract earthworms from the subsoil (Kramer et al., 2008). Adults are determined to the species level, juveniles to ecological groups. Abundance and biomass are determined for each taxonomic group.

\section{Crop Response Measurements}

Both below- and aboveground crop properties are measured periodically. The root mass depth distribution for treatments PG, NT, and CT is obtained from sampling soil cores (0-0.75-m depth) and washing out roots (Colombi and Walter, 2016). Root architectural traits and root anatomy are measured for the NT and CT treatments as described by Colombi and Walter (2016). Aboveground measures include biomass in the PG plots (separately for grass and legumes) for the first and last cut of a season and plant height, leaf area index, and shoot dry biomass at different stages in NT and CT plots (Colombi and Walter, 2016). Crop productivity on a per-hectare basis, being either grain or silage yield, is determined by harvesting multiple rows of a defined length within the plots (NT and CT).

\section{Initial Compaction Effects}

Soil compaction was performed on the ley on 26 Mar. 2014 at an average water content close to field capacity using a self-propelled two-axle fully loaded agricultural self-propelled vehicle. The vehicle was equipped with 1050/50R32 tires inflated to $330 \mathrm{kPa}$. The wheel load, measured with portable vehicle scales (Radlastwaage WL 103, Haenni Instruments AG) on site, was $8.9 \mathrm{Mg}$ on the front axle and 7.2 Mg on the rear axle (total vehicle mass: $32.2 \mathrm{Mg}$ ). Three vehicle passes (forward each time) were conducted on both CEP and CWT plots. The vehicle driving speed was maintained constant at $2 \mathrm{~m} \mathrm{~s}^{-1}$.

\section{Soil Moisture at Compaction}

The soil moisture conditions on the day of compaction (26 Mar. 2014) were "ideal" for effective soil compaction (i.e., the soil water content was close to the water content at the maximum Proctor density; e.g., Aragón et al., 2000; Botta et al., 2008). We measured average soil water suctions, obtained from tensiometers, of $54,60,86$, and $105 \mathrm{hPa}$ at the 0.1-, 0.2-, 0.4-, and 0.7-m depths, respectively. For the same depths, the volumetric water contents, $\theta$, obtained from FDR profilers, were $0.35,0.32,0.28$ and $0.24 \mathrm{~m}^{3}$ $\mathrm{m}^{-3}$, respectively, corresponding to gravimetric water contents, $w$, of $0.26,0.22,0.18$ and $0.15 \mathrm{~g} \mathrm{~g}^{-1}$, respectively. These values are slightly above the "optimum water content," $w_{\text {opt }}$, associated with the maximum density obtained in a Proctor test: Naderi-Boldaji et al. (2016) obtained $w_{\text {opt }}=0.18 \mathrm{~g} \mathrm{~g}^{-1}$ from soil sampled at the $0.25-\mathrm{m}$ depth in the immediate vicinity of the SSO (on the same field). This is identical to $w$ measured at $0.4 \mathrm{~m}$ but slightly lower than $w=0.22 \mathrm{~g} \mathrm{~g}^{-1}$ that we measured at $0.2 \mathrm{~m}$. Note that the optimum water content would be larger than the $0.18 \mathrm{~g} \mathrm{~g}^{-1}$ reported by Naderi-Boldaji et al. (2016) at the 0.1-m depth because of the higher SOC concentration in the topsoil, and lower than $0.18 \mathrm{~g}$ $\mathrm{g}^{-1}$ at $0.7 \mathrm{~m}$ because of the lower SOC concentration in the subsoil than at the 0.25 - $\mathrm{m}$ depth. Hence, $w$ at the time of the compaction event was close to $w_{\text {opt }}$ at all considered depths.

\section{Soil Stress, Surface Displacement, and Bulk Density}

The mean normal stress under the agricultural vehicle decreased from $\sim 150 \mathrm{kPa}$ at $0.2 \mathrm{~m}$ to $\sim 50 \mathrm{kPa}$ at $0.5 \mathrm{~m}$ (Fig. 4a). The increase in bulk density (Fig. 4b) was large at $0.1 \mathrm{~m}$ (from $\sim 1.3$ to $1.5 \mathrm{Mg}$ $\mathrm{m}^{-3}$ ) and $0.3 \mathrm{~m}$ (from $\sim 1.5$ to $1.6 \mathrm{Mg} \mathrm{m}^{-3}$ ), while there was only a small increase in bulk density at the $0.6-\mathrm{m}$ depth. The depth of 

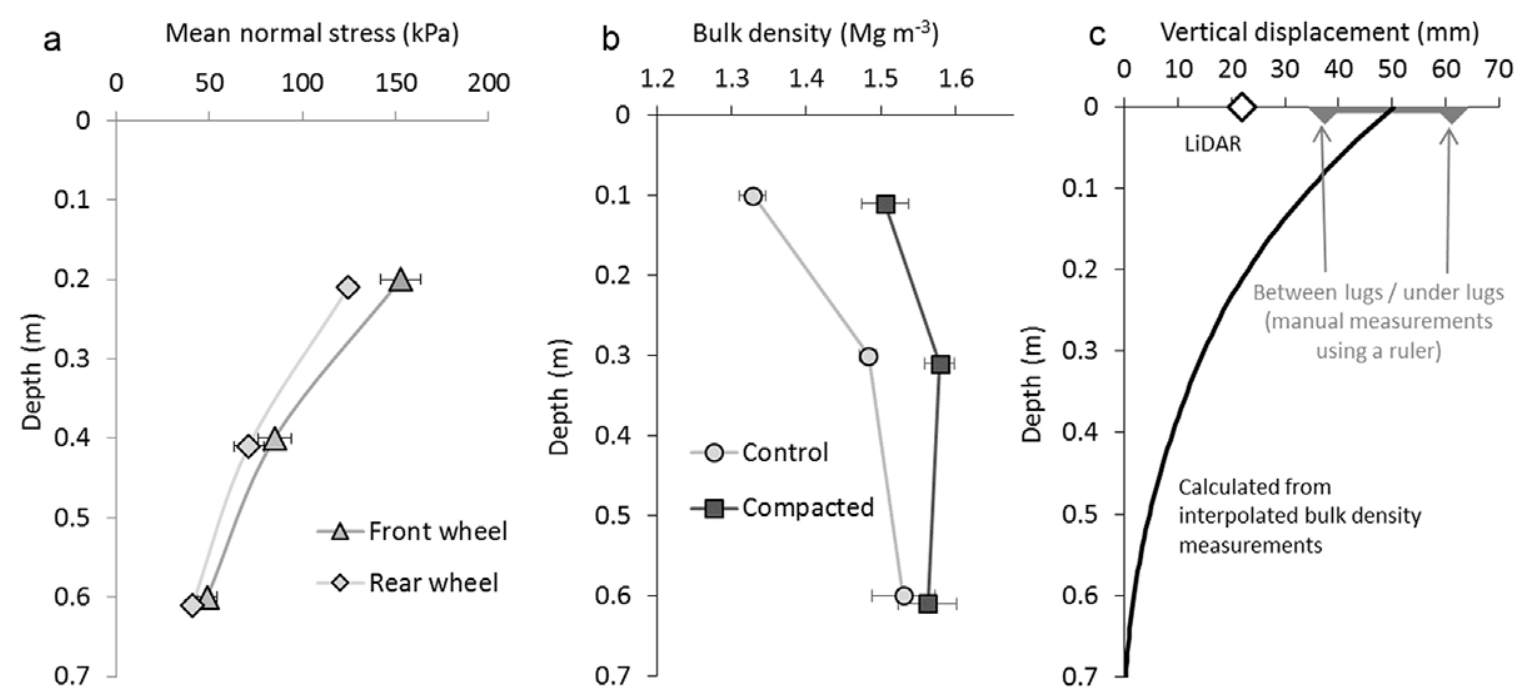

Fig. 4. (a) Mean normal stress under the agricultural vehicle (triangles: front wheel; rhombi: rear wheel) used for inflicting compaction; (b) average bulk density of uncompacted (circles) and compacted soil (squares), measured on samples collected $2 \mathrm{wk}$ after the compaction event; and (c) vertical displacement estimated from measured changes in bulk density (curve) and surface displacement (rut depth) obtained from lidar measurements (rhombi) and from manual measurements using a ruler (gray horizontal bar indicating the range resulting from readings between tire lugs and under tire lugs).

compaction of about half a meter is consistent with the results presented by Keller et al. (2012), who analyzed data from a large number of trafficking experiments on various soil textures and found that vertical strain was observed when the vertical stress exceeded $\sim 40$ $\mathrm{kPa}$. We calculated the vertical soil displacement from the measured changes in bulk density by interpolating between measuring depths, which resulted in a vertical displacement at the soil surface, i.e., rut depth, of $50 \mathrm{~mm}$ (Fig. 4c). This compared well with manual measurements using a ruler, from which we obtained rut depths between 37.5 (between tire lugs) and $61.3 \mathrm{~mm}$ (on tire lugs). The vertical surface displacement obtained from the lidar measurements (se above) was on average $22 \mathrm{~mm}$. The smaller surface displacement is explained by the fact that the reference plates were lying on the highest points of the soil surface and thus measured the minimum vertical displacement. Lidar measurements at $0.5,1$, and $2 \mathrm{~h}$ after compaction did not reveal any rebound.

We estimated the maximum Proctor density, $\rho_{\text {Proctor }}$ using Eq. [8] of Naderi-Boldaji et al. (2016) and the soil textural data given in Table 1 to 1.66 and $1.70 \mathrm{Mg} \mathrm{m}^{-3}$ for the 0.1 - and 0.3 -m depths, respectively. The degree of compactness, DC, given as the ratio of the actual bulk density to $\rho_{\text {Proctor }}$ increased due to compaction from 78 to $90 \%$ at the $0.1-\mathrm{m}$ depth, and from 88 to $94 \%$ at the $0.3-\mathrm{m}$ depth. Critical limits of DC with respect to crop yield reported in the literature are 84 to 87\% (Carter, 1990; Håkansson and Lipiec, 2000; NaderiBoldaji and Keller, 2016). Using the relationship between DC and the Dexter (2004) soil quality index $S$ developed by Naderi-Boldaji and Keller (2016), the DC values of the 0.1-m depth (topsoil) translate into $S$ values of 0.044 (uncompacted) and 0.027 (compacted), indicating a shift from "good" soil physical quality to "poor" soil physical quality. These estimations suggest that the compaction inflicted in the SSO created soil physical conditions that are considered poor and expected to be limiting for crop development.

\section{Soil Structure, Transport Properties, and Mechanical Impedance}

The internal soil deformation and increase in bulk density (i.e., decrease in total porosity; see above) due to the trafficking by the agricultural vehicle caused significant changes to the soil pore structure and soil transport properties (Table 3). Figure 5 presents

Table 3. Impact of compaction on selected soil physical properties from samples taken on 11 Apr. 2014, i.e., 2 wk after the compaction event. "Uncompacted" represents mean values for the uncompacted (no experimental compaction) reference plots, while "Compacted" represents mean values for the plots with compaction of the entire plot area.

\begin{tabular}{|c|c|c|c|}
\hline Soil property & Depth & Uncompacted & Compacted \\
\hline \multirow{4}{*}{ Total porosity $\left(\mathrm{m}^{3} \mathrm{~m}^{-3}\right)$} & $\mathrm{m}$ & & \\
\hline & 0.1 & $0.49(0.01) \dagger$ & $0.42(<0.01)$ \\
\hline & 0.3 & $0.44(<0.01)$ & $0.40(<0.01)$ \\
\hline & 0.6 & $0.42(<0.01)$ & $0.41(0.01)$ \\
\hline \multirow{3}{*}{$\begin{array}{l}\text { Air-filled porosity at } 100 \mathrm{hPa} \\
\text { water suction }\left(\mathrm{m}^{3} \mathrm{~m}^{-3}\right)\end{array}$} & 0.1 & $0.10(0.01)$ & $0.04(<0.01)$ \\
\hline & 0.3 & $0.07(<0.01)$ & $0.05(<0.01)$ \\
\hline & 0.6 & $0.06(<0.01)$ & $0.05(0.01)$ \\
\hline \multirow{3}{*}{$\begin{array}{l}\text { Relative gas diffusion coefficient } \\
\text { at } 100 \mathrm{hPa} \text { water suction }\end{array}$} & 0.1 & $0.024(0.001)$ & $0.006(0.001)$ \\
\hline & 0.3 & $0.011(0.001)$ & $0.005(<0.001)$ \\
\hline & 0.6 & $0.009(0.001)$ & $0.005(<0.001)$ \\
\hline \multirow{3}{*}{$\begin{array}{l}\text { Air permeability at } 100 \mathrm{hPa} \text { water } \\
\text { suction }\left(\mu \mathrm{m}^{2}\right)\end{array}$} & 0.1 & $56.9(1.1)$ & $3.2(1.4)$ \\
\hline & 0.3 & $17.7(1.0)$ & $4.2(1.2)$ \\
\hline & 0.6 & $10.9(1.3)$ & $3.0(1.1)$ \\
\hline \multirow{3}{*}{$\begin{array}{l}\text { Saturated hydraulic conductivity } \\
\qquad\left(\mathrm{mm} \mathrm{h}^{-1}\right)\end{array}$} & 0.1 & $421.3(1.1)$ & $108.6(1.2)$ \\
\hline & 0.3 & $194.9(1.1)$ & $78.2(1.1)$ \\
\hline & 0.6 & $191.0(1.3)$ & $74.2(1.2)$ \\
\hline $\begin{array}{l}\text { Soil surface water infiltration } \\
\left(\mathrm{mm} \mathrm{h}^{-1}\right)\end{array}$ & 0 & $485.5(50.9)$ & $0.7(0.6)$ \\
\hline
\end{tabular}




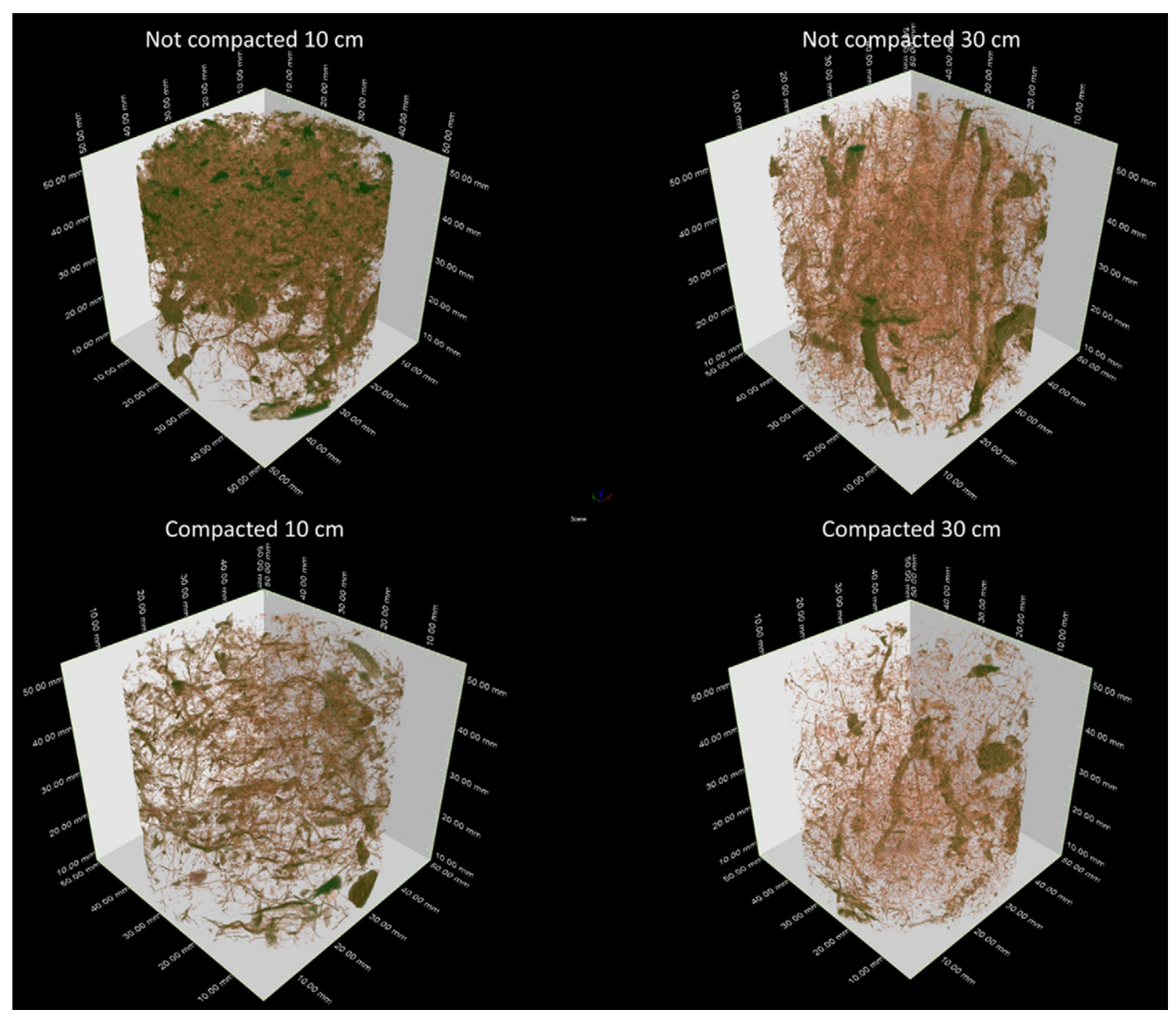

Fig. 5. Representative examples (100- $\mathrm{cm}^{3}$ samples) of soil pore structure detectable on micro computed tomography images (voxel size $60 \mu \mathrm{m}$, corresponding to a minimum pore width of $120 \mu \mathrm{m}$ ) for uncompacted (top) and compacted bare soil (bottom) at the 0.1- (left) and 0.3-m depth (right), sampled $2 \mathrm{wk}$ after the compaction event.

examples of the pore system (pores detectable on micro-computed tomography images, i.e., pore diameter $>120 \mu \mathrm{m}$ ) of compacted and uncompacted soil at the 0.1 - and 0.3 -m depths. The decrease in pore connectivity and in porosity is clearly visible at both depths, as also confirmed from measurements of air-filled porosity and gas transport properties (Fig. 6).

The decrease in porosity (Fig. 4b, 5, and 6a) drastically reduced the saturated hydraulic conductivity, $K_{\text {sat }}$ (Fig. 6b), air permeability, $k_{\mathrm{a}}$ (Fig. 6c), and the relative gas diffusion coefficient, $D_{\mathrm{p}} / D_{0}$ (Fig. 6d). The three different air-filled porosities per treatment and depth in Fig. $6 \mathrm{c}$ and $6 \mathrm{~d}$ reflect measurements obtained at three water suction values $(30,100$, and $300 \mathrm{hPa}$, respectively). A significant decrease in air-filled porosity and transport properties was measured at the $0.6-\mathrm{m}$ depth (Fig. 6), although there was only a small increase in bulk density (Fig. 4b). This shows that soil functions related to pore size distribution and pore connectivity are more sensitive to compaction than macroscopic properties such as bulk density (Horn, 2003). Compaction did not affect the relationship between $D_{\mathrm{p}} / D_{0}$ and $\varepsilon_{\mathrm{a}}$ (Fig. $6 \mathrm{~d}$ ), i.e., it did not affect the specific diffusivity $\left(c_{\mathrm{D}}=D_{\mathrm{p}} / D_{0} \times \varepsilon_{\mathrm{a}}{ }^{-1}\right)$, but $D_{\mathrm{p}} / D_{0}$ was substantially decreased in the compacted soil due to lower $\varepsilon_{\mathrm{a}}$. The slope of the $\log k_{\mathrm{a}}$ vs. $\log \varepsilon_{\mathrm{a}}$ relationship was slightly smaller for compacted soil (Fig. 6c), which would imply a slightly higher specific air permeability $\left(c_{\mathrm{A}}=k_{\mathrm{a}} \times \varepsilon_{\mathrm{a}}^{-1}\right)$ at small $\varepsilon_{\mathrm{a}}$ but a slightly lower $c_{\mathrm{A}}$ at high $\varepsilon_{\mathrm{a}}$. During recovery, it may be expected that $c_{\mathrm{A}}$ and $c_{\mathrm{D}}$ initially increase and later decrease again (Jarvis, 2007; Mossadeghi-Björklund et al., 2016).

Water infiltration at the soil surface, measured by means of a disk permeameter, exhibited a more pronounced reduction due to compaction than $K_{\text {sat }}$ in the soil profile. Infiltration rates decreased from 8 to $0.01 \mathrm{~mm} \mathrm{~min}^{-1}$, i.e., a decrease of almost three orders of magnitude. In other words, immediately following compaction, the soil surface became nearly impervious, which could be attributed to the excessive smearing of the soil surface by the 

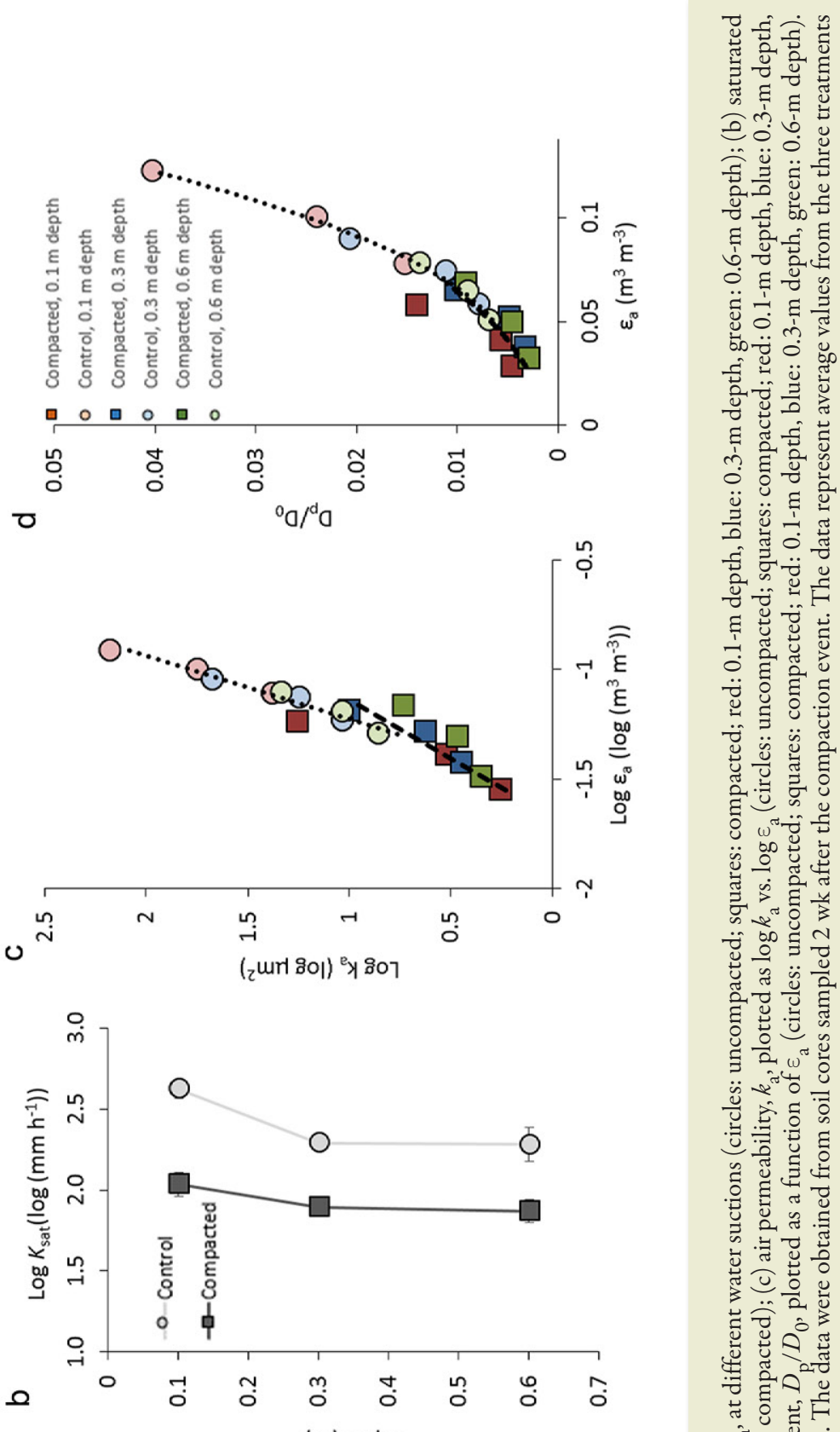

(iu) yzdə0
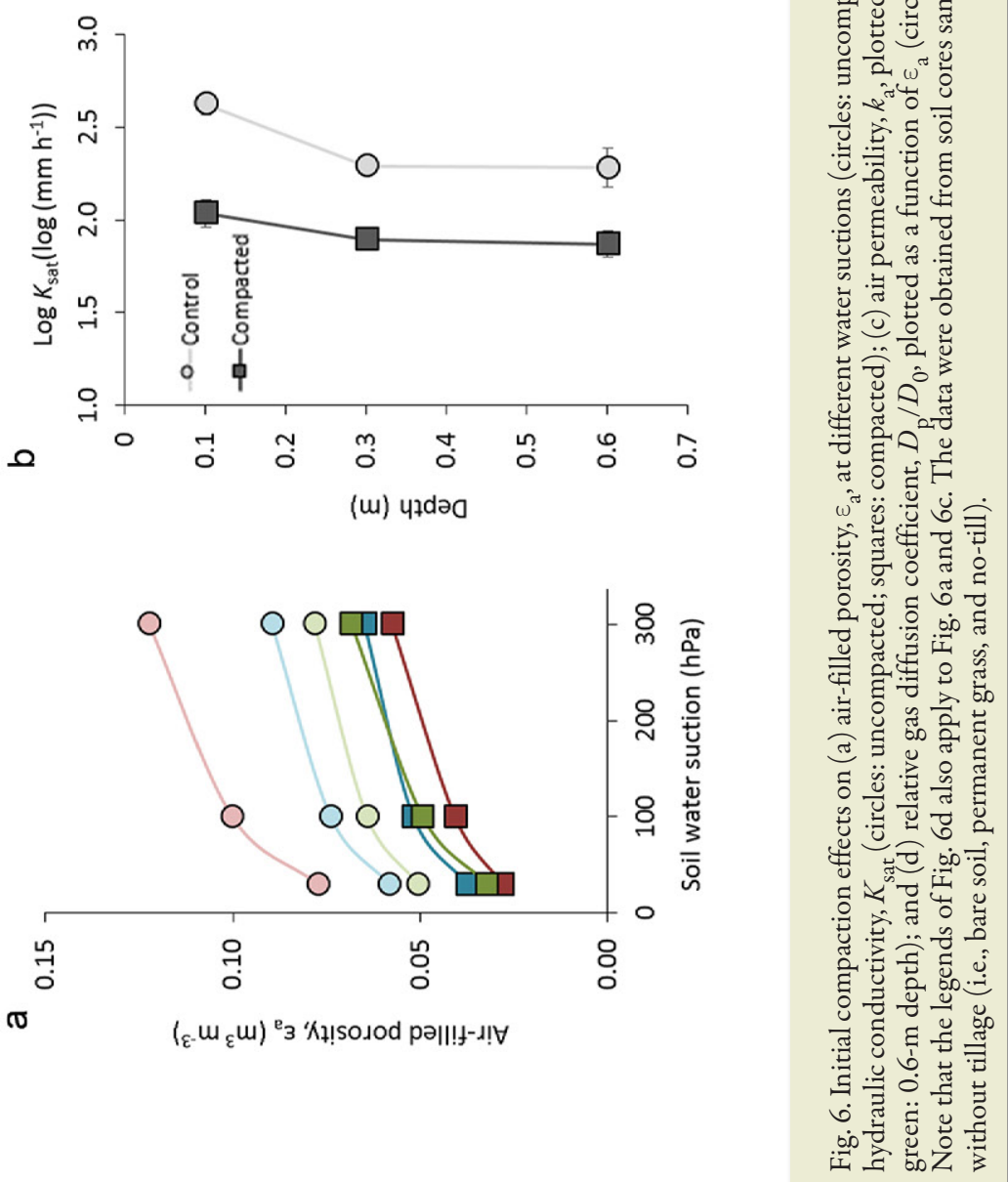
agricultural vehicle in addition to the effects of soil compaction. As a consequence, water ponded after rainfall in the compacted plots and in the wheel tracks. We measured an appreciable increase in mechanical resistance in the compacted topsoil ( $0-0.3-\mathrm{m}$ depth) relative to the uncompacted soil. Penetration resistance was almost 2.5 $\mathrm{MPa}$ in the compacted soil at the $0.1-$ to 0.25 -m depth, while the mechanical resistance at this depth was $\sim 1.3$ $\mathrm{MPa}$ in the uncompacted soil. Root elongation rates decrease with increasing soil penetration resistance (e.g., Dexter, 1987). A resistance of $2 \mathrm{MPa}$ is often considered critical for root growth (Taylor et al., 1966; da Silva et al., 1994); it may correspond to a value where root elongation rates are about half of the maximum root elongation rate (Dexter, 1987).

\section{Earthworms and Microbial Biomass}

The earthworm population was drastically reduced due to compaction. The estimated biomass in the compacted plots was only $30 \%$ (epigeics) to $41 \%$ (anecics) of that in the uncompacted soil (Table 4). The decrease was probably caused by increased mortality rates during the compaction event (i.e., during loading; McKenzie et al., 2009), as well as less favorable living conditions after compaction. There were no immediate effects of soil compaction on microbial biomass and respiration. However, we expect microbial communities and hence microbial biomass and respiration to adapt to the changed soil physical conditions with time (Hartmann et al., 2013).

\section{Electrical Resistivity Tomography}

An example of a preliminary analysis is given for the bare soil in Block B (Fig. 7). In this figure, the relative difference between the estimated electrical resistivity on 7 Apr. 2014 (12 d after compaction) and 21 Mar. 2014 (before the compaction) is shown. The soil electrical resistivity decreased by 10 to $15 \%$ for the part of the block that had undergone CEP treatment, and decreases were also found under the wheel tracks for the CWT treatment. These results were obtained by an inversion process that smoothens actual variations in resistivity, which implies that the compaction-affected depth range is probably smaller than the approximately 0 to $1 \mathrm{~m}$ that is indicated in this figure.

Table 4. Earthworm biomass 5 mo before and 2 mo after compaction. Mean values of five samplings per block (2013) and six samplings per treatment (two per block) in 2014.

\begin{tabular}{|c|c|c|c|c|}
\hline \multirow[b]{2}{*}{ Ecophysiological category } & \multirow[b]{2}{*}{2013} & \multicolumn{3}{|l|}{2014} \\
\hline & & Control & Compacted & $\begin{array}{l}\text { Compacted/ } \\
\text { control }\end{array}$ \\
\hline & $\longrightarrow$ & 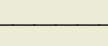 & $-\mathrm{kgha}^{-1}$ & 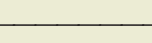 \\
\hline Epigeic & 106.7 & 114.7 & 34.6 & 0.30 \\
\hline Endogeic & 499.2 & 476.2 & 154.8 & 0.33 \\
\hline Anecic & 1581.5 & 1483.7 & 605.0 & 0.41 \\
\hline Total earthworm biomass & 2187.3 & 2074.5 & 794.4 & 0.38 \\
\hline
\end{tabular}

NOT COMPACTED TRACK COMPACTED FULL COMPACTED

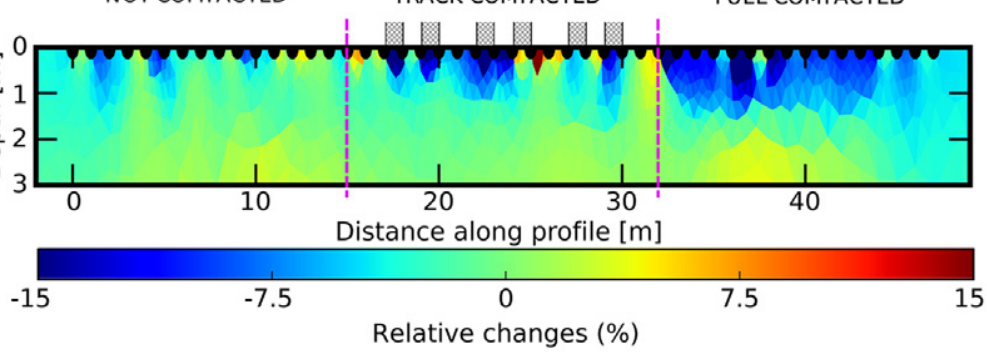

Fig. 7. Relative changes in inferred electrical resistivity between 7 Apr. 2014 (12 d after compaction) and 21 Mar. 2014 ( $5 \mathrm{~d}$ before compaction). The example shown is for bare soil in Block B. The patterns were similar for permanent grass and for the ther blocks.

\section{Outlook}

The SSO aims at providing long-term data on the post-compaction soil structure evolution under contrasting post-compaction soil management regimes. The long-term time scale and tight intervals of observations (continuous measurements provided by various sensor probes in combination with regular sampling and in situ measurements) are crucial. We expect that the observations will allow quantification of recovery rates and recovery times of compacted soil and a better understanding of the (relative importance of the) recovery mechanisms, considering both natural biotic and abiotic mechanisms as well as soil tillage. Furthermore, we expect that the generated knowledge will help define strategies and guidelines for accelerating soil structure recovery, and more generally, improving soil structure in modern agriculture.

Sampling and in situ measurements have so far been done at halfyearly intervals after the compaction event, and sensor probes were installed in the weeks after the compaction event. Initial compaction increased the soil bulk density to about $0.5-\mathrm{m}$ depth, decreased soil gas and water transport capability (air permeability, gas diffusivity, saturated hydraulic conductivity), and increased mechanical impedance. Water infiltration at the soil surface was drastically reduced (see also Fig. 8). Initial results from the post-compaction monitoring indicate projected recovery rates of years to decades, with different recovery rates for different properties and decreasing recovery rates with soil depth. Furthermore, the data indicate that soil tillage may immediately recover macroscopic soil total porosity but not soil functions (e.g., gas transport properties).

It would be highly desirable to establish similar SSOs under different soil and climatic conditions based on the concept outlined here. Additional SSOs could also include different compaction levels or different post-compaction soil management regimes. Data from other SSOs would increase our knowledge on how soil compaction recovery (and more generally, soil structure dynamics) is influenced by soil, climate, crops, and their interactions, allow estimates of compaction recovery rates and times across a wide range of soil and climatic conditions, and provide a wider basis for the development of soil management strategies. 

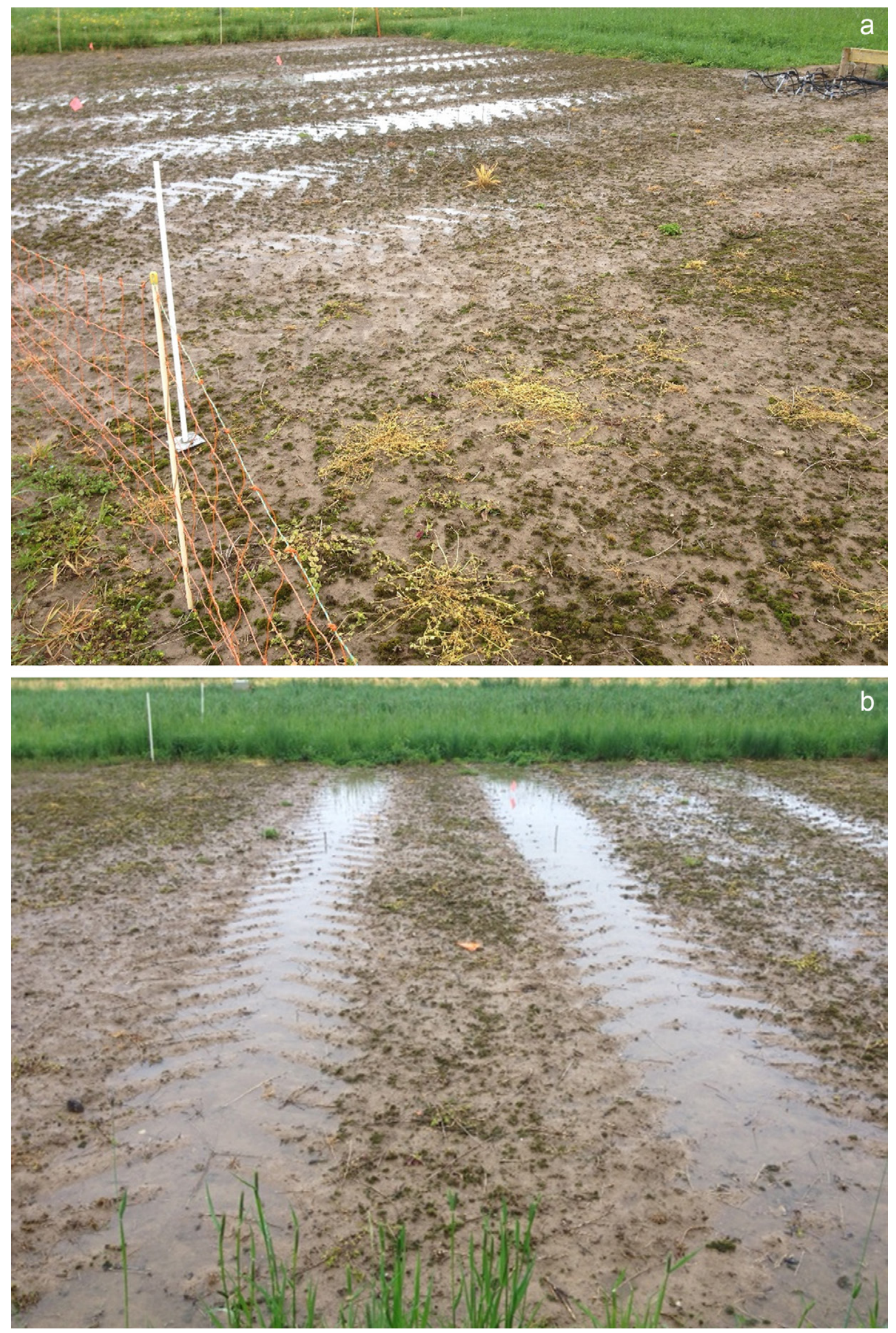

Fig. 8. Ponding water after rainfall in (a) compacted plots and (b) wheel tracks of the bare soil treatment in April 2015 (i.e., 1 yr after compaction). 


\section{Acknowledgments}

Financial support from the Swiss National Science Foundation (SNSF) through the National Research Program 68 "Soil Resources" is gratefully acknowledged (Project no. 406840 143061). We are thankful to Agroscope, Institute of Sustainability Sciences, for additional financial support. We thank Matthias Stettler (Bern University of Applied Sciences, School of Agricultural, Forest \& Food Sciences HAFL, Zollikofen, Switzerland) for help with the soil stress measurements. Lina Grahm, Annika Tella, Annika Messmer, Dr. Ingrid Martínez, Marlies Sommer, Andrea Bonvicini, and Susanne Müller (Agroscope, Soil Fertility and Soil Protection, Zürich, Switzerland), Patrick Hagenbucher and Milad Aminzadeh (Swiss Federal Institute of Technology ETH, Soil and Terrestrial Environmental Physics STEP, Zürich, Swit zerland), and Dr. Norbert Kirchgessner and Dr. Johannes Pfeifer (Swiss Federal Institute of Technology ETH, Crop Science, Zürich, Switzerland) are thanked for help with laboratory and field measurements. Dr. Peter Lehmann (Swiss Federal Institute of Technology ETH, Soil and Terrestrial Environmental Physics STEP, Zürich, Switzerland) is thanked for performing the randomization of sampling points. Philipp Walther, Fritz Käser, Stefan Schwarz, and An dres Sauter (Agroscope, trial support, Zürich, Switzerland) are thanked for performing the farming operations. Hans-Peter Müller, Hansueli Helbling, Theodor Neukom (Agroscope, Workshop, Zürich, Switzerland) and Beat Kürsteiner and Hubert Bollhalder (Agroscope, elec tronics workshop and support, Tänikon, Switzerland) are thanked for help with designing and constructing sensors and field installations.

\section{References}

Anderson, J.P.E., and K.H. Domsch. 1978. A physiological method for the quantitative measurement of microbial biomass in soil. Soil Biol. Biochem. 10:215-221. doi:10.1016/0038-0717(78)90099-8

Aragón, A., M.G. García, R.R. Filgueira, and Ya.A. Pachepsky. 2000. Maximum compactibility of Argentine soils from the Proctor test: The relationship with organic carbon and water content. Soil Tillage Res. 56:197-204. doi:10.1016/S0167-1987(00)00144-6

Arthur, E., P. Schjønning, P. Moldrup, M. Tuller, and L.W. de Jonge. 2013 Density and permeability of a loess soil: Long-term organic matter effect and the response to compressive stress. Geoderma 193-194:236245. doi:10.1016/j.geoderma.2012.09.001

Arvidsson, J., and I. Håkansson. 1996. Do effects of soil compaction persist after ploughing? Results from 21 long-term field experiments in Sweden. Soil Tillage Res. 39:175-197. doi:10.1016/S0167-1987(96)01060-4

ASTM. 1992. Annual book of ASTM standards. ASTM Int., West Conshohocken, PA.

Berli, M., C.G. Eggers, M.L. Accorsi, and D. Or. 2006. Theoretical analysis of fluid inclusion for in situ soil stress and deformation measurements. Soil Sci. Soc. Am. J. 70:1441-1452. doi:10.2136/sssaj2005.0171

Berisso, F.E., P. Schjønning, T. Keller, M. Lamandé, A. Ełana, L.W. de Jonge et al. 2012. Persistent effects of subsoil compaction on pore characteristics and functions in a loamy soil. Soil Tillage Res. 122:42-51. doi:10.1016/j.still.2012.02.005

Besson, A., M. Séger, G. Giot, and I. Cousin. 2013. Identifying the characteristic scales of soil structural recovery after compaction from three in-field methods of monitoring. Geoderma 204-205:130-139. doi:10.1016/j.geoderma.2013.04.010

Blackwell, P.S., M.A. Ward, R.N. Lefevre, and D.J. Cowand. 1985. Compaction of a swelling clay soil by agricultural traffic: Effects upon conditions for growth of winter cereals and evidence for some recovery of structure. J. Soil Sci. 36:633-650. doi:10.1111/j.1365-2389.1985.tb00365.x

Bolling, I. 1987. Bodenverdichtung und Triebkraftverhalten bei Reifen: Neue Mess- und Rechenmethoden. Ph.D. diss. Technische Univ. München, München, Germany.

Botta, G.F., D. Rivero, M. Tourn, F.B. Melcon, O. Pozzolo, G. Nardon, et al. 2008. Soil compaction produced by tractor with radial and cross-ply tyres in two tillage regimes. Soil Tillage Res. 101:44-51. doi:10.1016/j.still.2008.06.001

Capowiez, Y., S. Cadoux, P. Bouchand, J. Roger-Estrade, G. Richard, and H. Boizard. 2009. Experimental evidence for the role of earthworms in compacted soil regeneration based on field observations and results from a semi-field experiment. Soil Biol. Biochem. 41:711-717. doi:10.1016/j.soilbio.2009.01.006

Carter, M.R. 1990. Relative measures of soil bulk density to characterize compaction in tillage studies on fine sandy loams. Can. J. Soil Sci. 70:425-433. doi:10.4141/cjss90-042

Chamen, W.C.T., A.P. Moxey, W. Towers, B. Balana, and P.D. Hallett. 2015. Mitigating arable soil compaction: A review and analysis of available cost and benefit data. Soil Tillage Res. 146:10-25. doi:10.1016/j.still.2014.09.011

Colombi, T., and A. Walter. 2016. Root responses of triticale and soybean to soil compaction in the field are reproducible under controlled conditions. Funct. Plant Biol. 43:114-128. doi:10.1071/FP15194
Culley, J.L.B., B.K. Dow, E.W. Presant, and A.J. MacLean. 1982. Recovery of productivity of Ontario soils disturbed by an oil pipeline installation. Can. J. Soil Sci. 62:267-279. doi:10.4141/cjss82-031

da Silva, A.P., B.D. Kay, and E. Perfect. 1994. Characterization of the least limiting water range. Soil Sci. Soc. Am. J. 58:1775-1781. doi:10.2136/sssaj1994.03615995005800060028x

Dexter, A.R. 1987. Mechanics of root growth. Plant Soil 98:303-312. doi:10.1007/BF02378351

Dexter, A.R. 1991. Amelioration of soil by natural processes. Soil Tillage Res. 20:87-100. doi:10.1016/0167-1987(91)90127-J

Dexter, A.R. 2004. Soil physical quality: I. Theory, effects of soil texture, density and organic matter and effects on root growth. Geoderma 120:201-214. doi:10.1016/j.geoderma.2003.09.004

Drewry, J.J., R.J. Paton, and R.M. Monaghan. 2004. Soil compaction and recovery cycle on a Southland dairy farm: Implications for soil monitoring. Aust. J. Soil Res. 42:851-856. doi:10.1071/SR03169

Eggers, C.G., M. Berli, M.L. Accorsi, and D. Or. 2006. Deformation and permeability of aggregated soft earth materials. J. Geophys. Res. $111: B 10204$. doi:10.1029/2005JB004123

Farber, S.C., R. Costanza, and M.A. Wilson. 2002. Economic and ecological concepts for valuing ecosystem services. Ecol. Econ. 41:375-392. doi:10.1016/S0921-8009(02)00088-5

Flisch, R., S. Sinaj, R. Charles, and W. Richner. 2009. Grundlagen für die Düngung im Acker- und Futterbau (GRUDAF). Agrarforschung Schweiz 16(2):6-31.

Friedli, M., N. Kirchgessner, C. Grieder, F. Liebisch, M. Mannale, and A. Walter. 2016. Terrestrial 3D laser scanning to track the increase in canopy height of both monocot and dicot crop species under field conditions. Plant Methods 12:9. doi:10.1 186/s13007-016-0109-7

Gregory, A.S., C.W. Watts, W.R. Whalley, H.L. Kuan, B.S. Griffiths, P.D. Hallett, and A.P. Whitmore. 2007. Physical resilience of soil to field compaction and the interactions with plant growth and microbial community structure. Eur. J. Soil Sci. 58:1221-1232. doi:10.1111/j.1365-2389.2007.00956.x

Günther, T., C. Rücker, and K. Spitzer. 2006. Three-dimensional modeling and inversion of dc resistivity data incorporating topography: II. Inversion. Geophys. J. Int. 166:506-517. doi:10.1111/j.1365-246X.2006.03011.x

Håkansson, I., and J. Lipiec. 2000. A review of the usefulness of relative bulk density values in studies of soil structure and compaction. Soil Tillage Res. 53:71-85.

Håkansson, I., and R.C. Reeder. 1994. Subsoil compaction by vehicles with high axle load extent, persistence and crop response. Soil Tillage Res. 29:277-304. doi:10.1016/0167-1987(94)90065-5

Hallett, P.D., K.H. Karim, A.G. Bengough, and W. Otten. 2013. Biophysics of the vadose zone: From reality to model systems and back again. Vadose Zone J. 12(4). doi:10.2136/vzj2013.05.0090

Hamza, M.A., and W.K. Anderson. 2005. Soil compaction in cropping systems: A review of nature, causes and possible solutions. Soil Tillage Res. 82:121-145. doi:10.1016/j.still.2004.08.009

Hartmann, M., P.A. Niklaus, S. Zimmermann, S. Schmutz, J. Kremer, K. Abarenkov, et al. 2013. Resistance and resilience of the forest soil microbiome to logging-associated compaction. ISME J. 8:226-244. doi:10.1038/ismej.2013.141

Horn, R. 2003. Stress-strain effects in structured unsaturated soils on coupled mechanical and hydraulic processes. Geoderma 116:77-88. doi:10.1016/S0016-7061(03)00095-8

IUSS Working Group WRB. 2006. World reference base for soil resources: A framework for international classification, correlation and communication. World Soil Resour. Rep. 103. FAO, Rome.

Jarvis, N.J. 2007. A review of non-equilibrium water flow and solute transport in soil macropores: Principles, controlling factors and consequences for water quality. Eur. J. Soil Sci. 58:523-546. doi:10.1111/j.1365-2389.2007.00915.x

Jones, R.J.A., G. Spoor, and A.J. Thomasson. 2003. Vulnerability of subsoils in Europe to compaction: A preliminary analysis. Soil Tillage Res. 73:131-143. doi:10.1016/S0167-1987(03)00106-5

Jones, S.B., J.M. Wraith, and D. Or. 2002. Time domain reflectometry (TDR) measurement principles and applications. Hydrol. Processes 16:141153. doi:10.1002/hyp.513

Kaiser, E.A., T. Mueller, R.G. Joergensen, H. Insam, and O. Heinemeyer. 1992. Evaluation of methods to estimate the soil microbial biomass and the relationship with soil texture and organic matter. Soil Biol. Biochem. 24:675-683. doi:10.1016/0038-0717(92)90046-Z

Keller, T., J. Arvidsson, P. Schjønning, M. Lamandé, M. Stettler, and P. Weisskopf. 2012. In situ subsoil stress-strain behavior in relation to soil precompression stress. Soil Sci. 177:490-497. doi:10.1097/SS.0b013e318262554e 
Keller, T., S. Ruiz, J. Arvidsson, M. Stettler, and M. Berli. 2016. Determining soil stress beneath a tire: Measurements and simulations. Soil Sci. Soc. Am. J. 80:541-553. doi:10.2136/sssaj2015.07.0252

Klute, A., editor. 1986. Methods of soil analysis. Part 1. Physical and mineralogical methods. ASA and SSSA, Madison, WI.

Klute, A., and C. Dirksen. 1986. Hydraulic conductivity and diffusivity: Laboratory methods. In: A. Klute, editor, Methods of soil analysis. Part 1. 2nd ed. SSSA Book Ser. 5. SSSA and ASA, Madison, WI. p. 687-732.

Kramer, S., P. Weisskopf, and H.-R. Oberholzer. 2008. Status of earthworm populations after different compaction impacts and varying subsequent soil management practices. In: Soil tillage-New perspectives: 5th International Soil Conference ISTRO, Czech Branch, Brno. 30 June2 July 2008. Int. Soil Tillage Res. Organ., the Netherlands. p. 249-256.

Lal, R. 1993. Tillage effects on soil degradation, soil resilience, soil quality, and sustainability. Soil Tillage Res. 27:1-8. doi:10.1016/0167-1987(93)90059-X

Langmaack, M., C. Wiermann, and S. Schrader. 1999. Interrelation between soil physical properties and Enchytraeidae abundances following a single compaction in arable soil. J. Plant Nutr. Soil Sci. 162:517-525. doi:10.1002/(SICI) 1522-2624(199910) 162:5<517::AIDJPLN517>3.0.CO;2-3

Loomis, J., P. Kent, L. Strange, K. Fausch, and A. Covich. 2000. Measuring the total economic value of restoring ecosystem services in an impaired river basin: Results from a contingent valuation survey. Ecol. Econ. 33:103-117. doi:10.1016/S0921-8009(99)00131-7

MacNeil, M.A., N.A.J. Graham, J.E. Cinner, S.K. Wilson, I.D. Williams, J. Maina, et al. 2015. Recovery potential of the world's coral reef fishes. Nature 520:341-344. doi:10.1038/nature 14358

Martínez, I., A. Chervet, P. Weisskopf, W.G. Sturny, J. Rek, and T. Keller. 2016. Two decades of no-till in the Oberacker long-term field experiment: II. Soil porosity and gas transport parameters. Soil Tillage Res. 163:130-140. doi:10.1016/j.still.2016.05.020

McKenzie, B.M., S. Kühner, K. MacKenzie, S. Peth, and R. Horn. 2009 Soil compaction by uniaxial loading and the survival of the earthworm Aporrectodea calignosa. Soil Tillage Res. 104:320-323. doi:10.1016/j.still.2009.04.004

Mossadeghi-Björklund, M., J. Arvidsson, T. Keller, J. Koestel, M. Lamandé, M. Larsbo, and N. Jarvis. 2016. Effects of subsoil compaction on hydraulic properties and preferential flow in a Swedish clay soil. Soil Tillage Res. 156:91-98. doi:10.1016/j.still.2015.09.013

Naderi-Boldaji, M., and T. Keller. 2016. The degree of soil compactness is highly correlated with the physical quality index S. Soil Tillage Res. 159:41-46. doi:10.1016/j.still.2016.01.010

Naderi-Boldaji, M., P. Weisskopf, M. Stettler, and T. Keller. 2016. Predicting the relative density from on-the-go horizontal penetrometer measure- ments at some arable top soils in northern Switzerland. Soil Tillage Res. 159:23-32. doi:10.1016/j.still.2015.12.002

Orwin, K.H., and D.A. Wardle. 2004. New indices for quantifying the resistance and resilience of soil biota to exogenous disturbances. Soil Biol. Biochem. 36:1907-1912. doi:10.1016/j.soilbio.2004.04.036

Peng, X., and R. Horn. 2008. Time-dependent, anisotropic pore structure and soil strength in a 10-year period after intensive tractor wheeling under conservation and conventional tillage. J. Plant Nutr. Soil Sci. 171:936-944. doi:10.1002/jpln.200700084

Perroux, K.M., and I. White. 1988. Designs for disc permeameters. Soil Sci. Soc. Am. J. 52:1205-1215. doi:10.2136/sssaj1988.03615995005200050001x

Radford, B.J., D.F. Yule, D. McGarry, and C. Playford. 2007. Amelioration of soil compaction can take 5 years on a Vertisol under no till in the semiarid subtropics. Soil Tillage Res. 97:249-255. doi:10.1016/j.still.2006.01.005

Reiser, R., J. Rek, M. Holpp, H.-R. Oberholzer, T. Keller, and P. Weisskopf. 2012. Soil aeration and redox conditions monitored in a controlled traffic farming field trial. In: 19th ISTRO Conference, Montevideo, Uruguay. September 2012. Int. Soil Tillage Res. Organ., the Netherlands.

Schjønning, P., J.J.H. van den Akker, T. Keller, M.H. Greve, M. Lamandé, A. Simojoki, et al. 2015. Driver-pressure-state-impact-response (DPSIR) analysis and risk assessment for soil compaction: A European perspective. Adv. Agron. 133:183-237. doi:10.1016/bs.agron.2015.06.001

Suter, D., E. Rosenberg, R. Frick, and E. Mosimann. 2008. Standardmischungen für den Futterbau, Revision 2009-2012. Agrarforschung Schweiz 15:1-12.

Swiss Federal Research Stations. 1996. Referenzmethoden der Eidgenössischen landwirtschaftlichen Forschungsanstalten: 2. Bodenuntersuchung zur Standortcharakterisierung. Agroscope Reckenholz-Tänikon ART, Zürich.

Taylor, H.M., G.M. Roberson, and J.J. Parker, Jr. 1966. Soil strength-root penetration relations for medium- to coarse-textured soil materials. Soil Sci. 102:18-22. doi:10.1097/00010694-196607000-00002

Webb, R.H. 2002. Recovery of severely compacted soils in the Mojave Desert, California, USA. Arid Land Res. Manage. 16:291-305. doi:10.1080/153249802760284829

Webb, R.H., and H.G. Wilshire. 1980. Recovery of soils and vegetation in a Mojave Desert ghost town, Nevada, U.S.A. J. Arid Environ. 3:291-303.

Weisskopf, P., R. Reiser, J. Rek, and H.-R. Oberholzer. 2010. Effect of different compaction impacts and varying subsequent management practices on soil structure, air regime and microbiological parameters. Soil Tillage Res. 111:65-74. doi:10.1016/j.still.2010.08.007

Zhang, W., T.H. Ricketts, C. Kremen, K. Carney, and S.M. Swinton. 2007. Ecosystem services and dis-services to agriculture. Ecol. Econ. 64:253260. doi:10.1016/j.ecolecon.2007.02.024 